\title{
ENTRE LA RUPTURA Y LA CONTINUIDAD DE ESQUEMAS SOCIOEMOCIONALES EN LOS LIBROS DE LECTURA DE LA ESCUELA PRIMARIA EN EL TARDOFRANQUISMO (1959-1975) ${ }^{\S}$
}

\author{
Rupture and Continuity in the Socio-emotional Framework \\ of Primary School Reading Books in the later Years \\ of the Franco Regime (1959-1975)
}

\begin{abstract}
Ana Badanelli Rubio* y Kira Mahamud Angulo**
Fecha de recepción: 09/04/2015 • Fecha de aceptación: 04/05/2015
\end{abstract}

Resumen. El libro de lectura fue uno de los géneros textuales favoritos del franquismo, utilizado como vehículo privilegiado para la transmisión de conocimientos, valores y emociones. El artículo explora la evolución de sus características y contenidos en el tardofranquismo. Durante el primer y segundo franquismo los manuales escolares contenían una elevada dosis de adoctrinamiento ideológico, político y religioso. La inculcación de sentimientos y emociones en los textos también ha sido puesta de manifiesto. En aquellas primeras décadas del régimen el lenguaje empleado en la redacción de los manuales tenía objetivos manipulativos y persuasivos de control y moldeamiento de la estructura emocional de la infancia. Se cuestiona hasta qué punto y de qué manera la naturaleza del libro de lectura, el tipo de lecturas y los mensajes subyacentes se modificaron bajo la nueva política económica y la tecnocracia. La investigación examina las rupturas y continuidades que aparecen en los libros de lectura y en sus textos, prestando atención a las editoriales y los autores por un lado; y a los mensajes, al lenguaje escrito e icónico - y a las emociones que se transmiten a través de ambas vías- por otro. La apertura económica y el giro político del régimen

\footnotetext{
$\S$ Este artículo forma parte del proyecto «La dimensión afectiva de la socialización política. Emociones y sentimientos en los manuales escolares de la Transición democrática española» con referencia EDU2012-32162

* UNED. Facultad de Educación. Departamento de Historia de la Educación y Educación Comparada. Juan del Rosal, 14. 28040 Madrid. España. abadanelli@edu.uned.es

** UNED. Facultad de Educación. Departamento de Historia de la Educación y Educación Comparada. Juan del Rosal, 14.28040 Madrid. España.kmahamud@edu.uned.es
}

Cómo citar este artículo: Badanelli Rubio, Ana y Mahamud Angulo, Kira. «Entre la ruptura y la continuidad de esquemas socioemocionales en los libros de lectura de la escuela primaria en el tardofranquismo (1959-1975)», Historia y Memoria de la Educación, 2 (2015): 125-160. 
permitieron liftings estéticos y didácticos en los manuales. Pero los libros de lectura no solo cambiaron de fisonomía. El estudio descubre que el cambio de esquemas socioemocionales tuvo lugar de forma lenta y gradual; las emociones proyectadas y estimuladas se iban acercando al mundo infantil y a una lectura más constructiva, alejándose de objetivos sociopolíticos.

Palabras clave: Tardofranquismo. Libros de lectura. Emociones. Socialización política.

Abstract. Reading books were one of the favorite textual genres of the Franco Regime, used as a privileged vehicle for the transmission of knowledge, values and emotions. This article explores the evolution of their characteristics and contents during the late Franco dictatorship (tardofranquismo). During the first and second phases of Franco Regime, textbooks contained heavy doses of ideological indoctrination, both political and religious. The inculcation of emotions and sentiments in school texts has been demonstrated; in the early decades of the regime, the language employed in the writing of textbooks had the specific objective of manipulating and persuading as a means to control and shape the emotional structure of childhood. There is debate as to what extent and in what manner the nature of the texts (the kinds of readings and their underlying messages) were modified under the new economic policy and technocracy. The study examines ruptures and continuities that appear in reading books and in their texts, focusing on publishers and authors on the one hand - the messages and their written and iconic languages - and on the emotions that are transmitted through both routes on the other. The economic opening and political turn of the regime's later years did lead to certain aesthetic and didactic facelifts in the manuals. However, reading books not only changed their appearance; this study brings to light the changes in socio-emotional schemes, changes that took place slowly and gradually. The projected and stimulated emotions began to be directed more at the world of the children and towards a more constructive way reading, moving away from socio-political objectives.

Keywords: Later Franco Regime. Reading books. Emotions. Political socialization.

That a person can learn efficiently to read and yet not form a taste for reading good literature or without having curiosities aroused that will lead him to apply his ability to read to explore fields outside of what is conventionally termed good reading matter, are sad facts of experience. ${ }^{1}$

\footnotetext{
1 «Que una persona pueda aprender eficientemente a leer y sin embargo no formar un gusto por leer buena literatura o no sentir el despertar de la curiosidad que le conducirá a aplicar su habilidad para leer y explorar campos fuera de lo que convencionalmente se denomina buena materia de lectura, son hechos tristes de la experiencia». John Dewey, The Sources of a Science of Education (New York: Horace Liveright, 1929), 63.
} 


\section{POR QUÉ LOS LIBROS DE LECTURA}

"Así se aprende el odio en la escuela saudí», rezaba un titular del diario El País en el año 2006. ${ }^{2}$ "Los libros de texto empleados en la asignatura de estudios islámicos siguen fomentando la violencia contra el "infiel" », continuaba la noticia. El poder del llamado «libro de texto» no debe subestimarse (tampoco sobreestimarse) en ningún período histórico ni en ninguna sociedad, con independencia de la ideología dominante. Los libros de texto, como productos editoriales y culturales, como vehículos de los saberes establecidos con carácter obligatorio y oficial, como soportes didácticos del currículum prescrito y, en definitiva, como productos de consumo económico y cultural, resultan tentadores para quienes controlan el mercado y la educación.

¿Por qué nos centramos en el género textual del libro de lectura? Consideramos que tradicionalmente se trató de un género textual singular dentro del cual convivieron los libros creados ad hoc para la escuela y los que eran seleccionados como aptos para uso escolar de entre los libros de lectura infantil y juvenil existentes. ${ }^{3}$ Tiana comenta, por ejemplo, cómo El Quijote, utilizado como texto de lectura escolar, servía para «educar deleitando, siguiendo el camino del ejemplo». ${ }^{4}$ Su misión era múltiple puesto que no solo pretendían enseñar a leer, sino ofrecer "narraciones de tipo utilitario». ${ }^{5}$

Patterson, Cormack y Green, en su estudio sobre las cartillas de enseñanza y aprendizaje de la lectura en Inglaterra, afirman que «from their inception, primers were used in the formation of particular types of conduct, not in a cause-and-effect relation, but through a complex intermeshing of texts and strategies for teaching reading and for teaching the construction of particular modes of being». ${ }^{6}$

\footnotetext{
2 Nina Shea, «Así se aprende el odio en la escuela saudí», El País, 28 de mayo de 2006.

${ }^{3}$ Real Decreto de 6 de marzo. Recogido en Colección legislativa de Instrucción Pública, Años 1900-1935, vol. 22: 140-142.

${ }^{4}$ Alejandro Tiana, «El Quijote y la educación», Revista de Educación (número extraordinario) (2004): 217.

${ }^{5}$ Montserrat Huguet, «Memoria del primer franquismo. Mujeres, niños y cuentos de infancia», en Tessere trame, narrare storie. Le donne e la scrittura per l'infanzia, ed. Antonella Cagnolati (Roma: Aracne, 2013), 132.

6 «Desde su comienzo, las cartillas fueron usadas para la formación de tipos particulares de conductas; no es una relación de causa-efecto, sino a través de un complejo engranaje entre textos y estrategias para enseñar a leer y para enseñar la construcción de modos particulares de ser». Annette Joyce Patterson, Phillip Anton Cormack y William Charles Green, «The child, the text and the teacher: reading primers and reading instruction», Paedagogica Historica: International Journal of the History of Education, 48 (2), (2012): 190.
} 
Los libros de lectura, al entrar a formar parte de los materiales y recursos escolares, se convirtieron en lecturas controladas y guiadas, ${ }^{7}$ que formaban parte de una estrategia educativa de mayor alcance. En efecto, desde «la segunda mitad del siglo XIX afloraron determinados libros de lectura para niños y para niñas, que conocieron una larguísima pervivencia en cuanto a ediciones y que sin ser libros de texto puros, en el sentido que hoy entendemos, tampoco entraban en la categoría plena de lo literario", ${ }^{8}$ fueron aprobados para su uso en las escuelas ${ }^{9}$ pero iban dirigidos a niños y niñas con lecturas bien diferenciadas.

Los libros de lectura, que tantas y tan importantes funciones pueden cumplir dentro del quehacer escolar, ${ }^{10}$ fueron los favoritos de la escuela del primer y segundo franquismo. Efectivamente, su naturaleza más informal, menos tediosa y más cercana a lo lúdico, los convertía - y convierte todavía- en manuales atractivos y con grandes posibilidades de llegar al alumno de una manera distinta a la de otro libro de texto de cualquier otra disciplina. ${ }^{11}$ Constituyeron, a juicio de algunos autores, el género dominante en la escuela de la posguerra. Claro que para lograr los propósitos de adoctrinamiento ideológico se convirtieron en manuales sesgados, estereotipados y

\footnotetext{
${ }^{7}$ Anne Marie Chartier y Jean Hébrard, Discursos sobre la lectura 1880-1980 (Barcelona: Gedisa, 1994).

8 Jaime García Padrino, Así pasaron muchos años. (En torno a la Literatura Infantil Española) (Cuenca: Ediciones de la Universidad de Castilla la Mancha, 2001), 243.

${ }^{9}$ García Padrino, Así pasaron muchos años, 243.

${ }^{10}$ Carmen García Crespo, «La ideología del franquismo en los libros de lectura escolares. El componente religioso", en Sociedad, ideología y educación en la España contemporánea, eds. J. A. Cieza García y otros (Salamanca: ICE de la Universidad de Salamanca, 1985), 116.

${ }_{11}$ Aunque los libros de texto de historia han sido muy populares entre los investigadores, los estudios sobre el adoctrinamiento ideológico a través de los manuales escolares durante el franquismo han contado con los libros de lectura como género textual de gran relevancia. Véase, por ejemplo, Gregorio Cámara Villar, Nacionalcatolicismo y escuela. La socialización política del franquismo (1936-1951) (Jaén: Hesperia, 1984); Manuela López Marcos, El fenómeno ideológico del franquismo en los manuales escolares de enseñanza primaria (1936-1945) (Madrid: UNED, 2001); Catalina Albacete García, «La enseñanza de la geografía escolar a través de los libros de lecturas geográficas. Primer tercio del siglo XX», en El currículum: historia de una mediación social y cultural. IX Coloquio de Historia de la Educación (Granada: Departamento de Pedagogía-Universidad de Granada, 1996), II, 231-239; José Luis Álvaro Estramiana e Ignacio Monge Lanzas, "La familia en los libros de texto de lectura infantil», Revista de Educación, 275 (1984): 73-92; Antonio Castillo Gómez, Una historia mínima del libro y la lectura (Madrid: Siete Mares, 2004); Pedro C. Cerrillo y Carlos J. Martínez Soria (eds.), Lectura, infancia y escuela. 25 años de libro escolar en España: 1931-1956 (Cuenca: Universidad de Castilla-La Mancha, 2009); Víctor Infantes, François López y Jean François Botrel (dir.), Historia de la edición y de la lectura en España, 1472-1914 (Madrid: Fundación Germán Sánchez Ruipérez, 2003); Roberta Paula Spregelburd y María Cristina Linares (orgs.), La lectura en los manuales escolares. Textos e imágenes (Luján: UNNE/UNLu/SPU, Imprenta de la Universidad Nacional de Luján, 2009).
} 
poco originales que se alejaron de la riqueza que puede ofrecer la literatura infantil, acercándose más a la creación e invención de historias insulsas que rozaban el aburrimiento, pero también historias trágicas que despertaban sentimientos de compasión e historias heroicas que alimentaban el patriotismo. Se encuentran además libros de lectura de diversa índole, desde lecturas específicas para niñas, pasando por lecturas esencialmente religiosas o históricas y patrióticas, hasta lecturas variadas que cubren un amplio espectro de temas. La literatura infantil de la época sufrió la misma suerte de «confinamiento [...] a un estrecho reducto de moralismo didáctico donde imperaban los valores religiosos y unos modelos de patriotismo heroico que apenas dejaban lugar para el humor, y menos aún para el humor crítico», apunta María Victoria Sotomayor. ${ }^{12}$

En la obra de Montilla, Selección de libros escolares de lectura, una de sus conclusiones finales es precisamente que el libro de lectura es el favorito del Magisterio y de los escolares. ${ }^{13}$

Se puede afirmar que el contenido de libro predilecto, leído y releído por el niño, sin que su interés se agote durante determinados períodos de su evolución psíquica, se incorpora a él, enriqueciendo el mundo de sus ideas, de sus inclinaciones y de sus sentimientos. ¡Tal es la influencia que ejerce el libro de lectura! ${ }^{14}$

Hacia finales de la década de los cincuenta comenzó la modificación de la concepción del libro de lectura dentro del conjunto de libros de texto, como demuestra el artículo publicado por el inspector de Enseñanza Primaria, Modesto Merino. Asegura el autor en primer lugar, y en la línea de nuestro argumento, que el libro escolar debería ser reflejo del mundo y sus cosas, de experiencia y emociones, de victorias y fracasos, en los que el niño se va a sumir. Pero a continuación afirma que había que distinguir el libro de lectura del libro de texto, que, comúnmente, desarrolla los planes de estudio en un orden dado. Indica que los libros de lectura son más bien

\footnotetext{
12 María Victoria Sotomayor, "El humor en la literatura infantil del franquismo», Anales de Literatura Española, 19 (2007): 239.

13 Esta obra recoge los resultados de los cuestionarios pasados a maestros de escuelas unitarias y mixtas, y a inspectores de enseñanza primaria de toda España pidiéndoles un juicio crítico sobre los libros escolares conocidos y utilizados por ellos.

14 Francisca Montilla, Selección de libros escolares de lectura (Madrid: CSIC, 1953), 48.
} 
instrumentación complementaria de todas las asignaturas escolares. ${ }^{15} \mathrm{El}$ mismo inspector añade que:

[e]n los últimos grados de la Escuela primaria los libros de lectura son tan indispensables que llegan a ser el mejor procedimiento didáctico para la adquisición de saberes científicos o especializados. La vida de los grandes hombres, los inventos, las maravillas de la tierra, los misterios del mar y de los astros, los grandes descubrimientos, la poesía, lo romántico e investigativo, seduce a los muchachos con variaciones sentimentales ${ }^{16}$ y apreciativas entre los dos sexos. ${ }^{17}$

El editorial de la revista Vida Escolar de junio-julio de 1959 se dedicó a los libros escolares, indicando que «los de lectura levantan bandadas de interrogantes, de difícil contestación» y que se había llegado a un punto en que el libro de estudio era casi un libro de lectura. ${ }^{18}$

Los libros de lecturas infantiles (no de literatura infantil) también comenzaron a distinguirse de los libros escolares de lectura hacia finales de la década de los sesenta. En 1958 se convocó por primera vez el premio Lazarillo de literatura infantil y juvenil, impulsado por el Instituto Nacional del Libro Español (INLE). Es necesario destacar que el primer galardonado fue el inspector de Enseñanza Primaria, Alfonso Iniesta Corredor, ${ }^{19}$ por su libro de lecturas religiosas Dicen las florecillas. (Estampas franciscanas). ${ }^{20}$ La nota de prensa publicada en el diario ABC con motivo del galardón informó de cómo asistieron «entidades del Magisterio de toda España» al homenaje organizado al autor. ${ }^{21} \mathrm{El}$ primer premio de literatura infantil se otorgó a un libro de lecturas religiosas igual a otros que se usaban en las escuelas de primera enseñanza. A partir de la siguiente convocatoria, el premio rompió completamente con la línea marcada por el primer galardonado. ${ }^{22}$

\footnotetext{
15 Modesto Merino, «Concurso Permanente. Los libros y los niños», Vida Escolar, 7 (abril 1959): 42.

16 La cursiva es nuestra.

17 Modesto Merino, «Concurso Permanente», 42.

18 Editorial, «En torno a los libros escolares», Vida Escolar, 9-10 (junio-julio 1959): 2. El editorial divide los libros escolares en cuatro clases: de lectura, de materias, de consulta y de recreo. Quiere esto decir que los de lectura tenían su propia entidad.

${ }^{19}$ Consejero Nacional de Educación e Inspector Central de Educación.

20 Alfonso Iniesta, Dicen las florecillas. (Estampas franciscanas) (Gerona: Dalmau Carles, 1958). En 1964, el libro de lectura iba por la 5. ${ }^{a}$ edición y en 1969 por la $6{ }^{2}$.

${ }^{21} A B C$, domingo 25 de enero de 1959, 82.

22 García Padrino, Así pasaron muchos años, 151.
} 
Se confirma el hecho de iniciarse una reflexión dentro de la comunidad educativa en torno al libro de lectura como género textual, a su naturaleza y función dentro del conjunto de libros de texto. El final de la década de los cincuenta marcó el comienzo de un giro en la redacción y edición del libro de lectura que iba a producirse de forma muy gradual, lo que supondría muchos años de convivencia entre los libros de lectura modernos y los tradicionales. Coincidió la época de transformación del libro de lectura con la transformación de la estructura social de la sociedad española desde 1959.

\section{POR QUÉ EL CONTENIDO EMOCIONAL}

Más allá del objeto de estudio - los manuales utilizados para la enseñanza de la lectura-, este trabajo se centra fundamentalmente en el análisis de su contenido emocional. Son varios los motivos que nos conducen a este estudio de los aspectos emocionales. El primero de ellos y, como antecedente de este trabajo, la lectura de una tesis doctoral leída en el centro de investigación MANES ${ }^{23}$ que defendió y mostró cómo los manuales escolares del primer franquismo (1939-1959) estaban marcados por unas directrices didácticas de orden emocional en la forma, puesto que se dan instrucciones a los maestros para educar emocionando, y en el fondo, en cuanto que se instruye a los niños y a las niñas sobre a quién, cuánto y cómo amar, detestar, temer...

En particular adoctrinaban emocionalmente a la infancia escolarizada a través de una serie de conceptos y figuras político-religiosas con carga afectiva, del lenguaje metafórico y de la construcción de identidades individuales (masculina y femenina) y colectivas, basadas en determinados sentimientos ideológicamente condicionados, que además estaban pensados para influir, no solo en el ser del individuo, sino también en el actuar del mismo.

Sirva como ejemplo la crítica que hace un inspector de Enseñanza Primaria a los libros de texto de la Segunda República, anunciando sin tapujos la llegada de nuevos manuales cargados de una corriente afectiva confortadora: «Nuevos libros escolares contribuyen a lograr la transformación anhelada. Al frío laico y neutro, ha sucedido una corriente afectiva confortadora». ${ }^{24}$

\footnotetext{
${ }^{23}$ Kira Mahamud Angulo, Adoctrinamiento emocional y socialización política en el primer franquismo (1939-1959). Emociones y sentimientos en los manuales escolares del enseñanza primaria. Tesis Doctoral, UNED (2012).

${ }^{24}$ Alfonso Iniesta, «Transformación de la Escuela Primaria Española», Revista Nacional de Educación, Año III (enero, 1943): 90.
} 
En segundo lugar, encuadramos este trabajo en un marco teórico en expansión que responde al surgimiento del interés por las emociones y los sentimientos en las ciencias sociales y humanas, tendencia que es conocida en el mundo académico como the affective turn. ${ }^{25}$ Supone un nuevo enfoque y un cambio de dirección de la investigación científica que en realidad comenzó en la década de los noventa del pasado siglo, pisando firme en la primera del siglo XXI. La función que desempeñan los sentimientos y las emociones en la vida individual y social de las personas es de más largo alcance de lo que algunos sociólogos y filósofos pensaban en el pasado, «idealizando la razón y endemoniando las emociones». ${ }^{26}$ Su influencia en la educación y en el proceso de socialización política es inestimable.

Los artículos de revistas, ${ }^{27}$ los monográficos de las revistas especializadas, ${ }^{28}$ la proliferación de publicaciones, junto a las reuniones científicas en torno a la temática desde un gran abanico de perspectivas de estudio, ${ }^{29}$ y la creación de fundaciones e instituciones dedicadas a la educación emocional, así como la aparición de programas de estudio y proyectos de investigación, constituyen una evidencia más de este florecimiento.

Las emociones y los sentimientos en sí mismos pueden y deben ser examinados como categorías analíticas, puesto que emergen como recursos di-

${ }^{25}$ El término es acuñado en el año 2007 de la mano de la socióloga Patricia Ticineto Clough, y su colega Jean Halley, en el libro titulado, The Affective Turn: Theorising the Social (Duke: University Press, 2007).

${ }^{26}$ Michael Stocker, Valuing emotions (Cambridge: CUP, 1996), XIX.

${ }^{27}$ Citamos, por ejemplo, dos trabajos de disciplinas muy distantes: Aurora Bernal Martínez de Soria, "Tendencia educativa en auge: la "omnipresencia" de la educación emocional», en Ideales de Formación en la Historia de la Educación, coord. Javier Vergara, Fermín Sánchez y Beatriz Comella (Madrid: Editorial Dykinson, S.L., 2011), 769-794, y Jo Labanyi, "Doing Things: Emotion, Affect, and Materiality», Journal of Spanish Cultural Studies, 11 (3 y 4), (2010): 223-233. Se trata de un número especial titulado Cultural/Political Reflection - Lines, Routes, Spaces.

${ }_{28}$ Algunos de estos monográficos son: «Educar para el amor», Padres y Maestros, 281 (enero de 2004); «La educación emocional: sentimientos, cultura y comunicación», Cuestiones Pedagógicas (2008); y «Emotions in the History of Education: Strategies, Contexts, Impacts», Jahrbuch für Historische Bildungsforschung, 18 (2012).

${ }^{29}$ Citamos, a modo de ejemplo de la diversidad de campos de estudio, tres encuentros organizados por distintas disciplinas: (1) el Congreso Internacional titulado «Conocer, conmover. Las emociones de la cultura y la cultura de las emociones: el orden de la sensibilidad moderna», organizado por el Grupo de Investigación sobre Cultura, Edición y Literatura en el Ámbito Hispánico siglos XIX-XXI (GICELAH), que tuvo lugar los días 15, 16 y 17 de marzo de 2010 en el Centro Superior de Investigaciones Científicas (CSIC); (2) el X Congreso Internacional de Psicología Jurídica y Criminológica, titulado «Crimen, Emociones y Castigo", celebrado los días 25, 26 y 27 de noviembre de 2011 en la Ciudad de Puebla, México; y (3) la «Moral Emotions and Risk Politics Conference», que se celebró en la Delft University of Technology de Holanda, los días 20 al 22 de agosto de 2012. 
dácticos de obligado uso para el maestro en el franquismo (sentir las lecciones que impartían, enseñar emocionando al alumno y hacer que sintieran las lecciones), así como contenidos específicos de enseñanza (instrucciones precisas sobre cómo y a quién amar, temer, admirar...) y finalmente como indicadores de comportamientos y conductas (manifestación explícita y pública de los sentimientos). ${ }^{30}$

Los manuales escolares de la posguerra contienen multitud de referencias a los sentimientos: el amor (a la patria, a Dios, etc.), el odio (al otro, al enemigo, etc.), el miedo (al infierno, al demonio, al castigo, etc.), el orgullo o la vergüenza. Durante las décadas de los cuarenta, cincuenta y gran parte de los sesenta, los sentimientos y las emociones incorporados a los contenidos de los manuales escolares responden a una estrategia político-educativa de las autoridades políticas, religiosas y académicas, para la transmisión de su ideología y el logro de sus intereses. El lenguaje empleado en la redacción de los manuales escolares tiene objetivos manipulativos y persuasivos de control y moldeamiento de la estructura emocional y sentimental de la infancia. Durante esta época resalta el poder del colectivo de autores para hacer circular, expandir, difundir y penetrar el componente emocional del mensaje ideológico. Los autores, si bien manejaban un estilo muy similar, estampaban con su pluma un sello personal, y a la vez colectivo, del gremio y oficio de redactores de manuales. Los manuales sufrían un gran impacto procedente de la identidad individual y colectiva de los autores o autoras, de sus creencias, principios y sentimientos. Los libros escolares cumplían con las características estilísticas del contexto, dentro de las cuales estaban las lingüísticas, pero a la vez eran productos muy personales y personalizados.

El presente trabajo responde a la inquietud acerca de si estas características singulares de los libros de lectura del primer y segundo franquismo - y de sus autores- se mantuvieron en los libros de la segunda generación de textos en las últimas décadas del franquismo. ${ }^{31} \mathrm{Al}$ comprobar que reunían una serie de características ligeramente diferentes marcadas por la tecnocracia, el final de la autarquía y el inicio de la apertura internacional del régimen, nos detenemos a examinar qué rasgos determinan su evolución.

\footnotetext{
30 Mahamud Angulo, Adoctrinamiento emocional, 27.

31 Agustín Escolano Benito, «La segunda generación de manuales escolares», en Historia ilustrada del libro escolar en España: de la posguerra a la reforma educativa, coord. Agustín Escolano Benito (Madrid: Fundación German Sánchez Ruiperez, 1997), 19-48.
} 
¿Qué ocurrió con el libro de lectura en el tardofranquismo? Si bien fue perdiendo visibilidad y relevancia en el conjunto de nuevos manuales escolares que brotaban de las nuevas editoriales, ¿modificó también su estilo narrativo y se alejó del modelo emotivo y sentimental de las primeras décadas del franquismo? ¿Quiénes relevaron a los autores más prolíficos de este género textual?

El objetivo principal de la investigación responde a la pregunta acerca de cuál es la evolución de los libros de lectura en cuanto a su estética y los contenidos vinculados a la dimensión afectiva de la socialización política. Para lograr este objetivo ha sido necesario comprobar cuáles son los cambios más significativos que inciden en sus contenidos. En primer lugar, qué editoriales continuaron publicando este tipo de textos durante el tardofranquismo y cuáles surgieron en la época. En segundo lugar, qué autores continuaron publicando durante el tardofranquismo y quiénes fueron los nuevos autores que relevaron al colectivo anterior.

Se han analizado las persistencias y las novedades encontradas entre los años 1959 y 1975 con respecto a las primeras décadas del régimen, teniendo en cuenta dos hechos que afectan directamente a la evolución que sufrió el mundo educativo en general, y en particular el libro de lectura: el surgimiento de nuevas editoriales como Anaya y Santillana - y sus autores-en los años sesenta, y la aprobación de la Ley 14/1970 General de Educación y Financiamiento de la Reforma Educativa (en adelante, LGE) que marcó un antes y un después en el sistema educativo español.

\section{APUNTES METODOLÓGICOS}

Para conocer las características de la producción de los libros de lectura publicados durante el periodo que abarca este trabajo, y con el objetivo de poder elegir una muestra significativa en la que basar el análisis, se ha realizado un trabajo de cuantificación que sirve como soporte para recoger los primeros datos significativos acerca de la evolución de la fuente. A través de esta cuantificación ha sido posible recoger información clave como el nombre del autor, el año de edición y el nombre de la editorial de cada texto localizado. ${ }^{32}$ En la Tabla 1 se observa con claridad qué autores y qué editoriales publicaron textos de lectura.

\footnotetext{
32 Para la localización de estos textos se ha utilizado la Biblioteca del Centro de Investigación MANES que cuenta en la actualidad con más de 7000 ejemplares editados desde finales del siglo XVIII hasta nuestros días.
} 
Tabla 1. Vinculación de autores y editoriales

\begin{tabular}{|c|c|c|}
\hline AFRODISIO AGUADO & Parravicini, Luigi & MIGUEL ÁNGEL SALVATELLA \\
\hline Benítez Franco, Bartolomé & IMPRENTA CATÓLICA & Díaz Santillana, Santos \\
\hline Maíllo, Adolfo & Herrera Oria, Enrique & Domínguez Esteban, José León \\
\hline Manzanares Beriain, Alejandro & LIBRERÍA INTERNACIONAL & Fernández Rodríguez, Antonio \\
\hline ESCUELA ESPAÑOLA & Salaverría, José María & Maíllo, Adolfo \\
\hline González, Nicolás Ruiz & HIJOS DE ANTONIO PÉREZ & Ortiga, Emilio \\
\hline Serrano de Haro, Agustín & Gabriel y Galán, José María & Llano, Alberto \\
\hline Solana, Ezequiel & LÓPEZ MEZQUIDA EDITOR & Estrada, Adelina \\
\hline HERNANDO & Pérez Rodrigo, Ángel & MIÑóN \\
\hline Herrero y Ayora, Melchora* & $\begin{array}{l}\text { LIBRERÍA MONTSERRAT DE SUCESOR } \\
\text { DE HIJO DE J. ROCA Y BROS }\end{array}$ & Álvarez Pérez, Antonio \\
\hline Manzanares Beriain, Alejandro & Lista, Aurora $^{* *}$ & Ferrándiz Casares, Josefina \\
\hline Torres, Federico & $\begin{array}{c}\text { LIBRERÍA GENERAL DE VICTORIANO } \\
\text { SUAREZ }\end{array}$ & $\begin{array}{c}\text { IMPRENTA DE LA VIUDA E HIJOS } \\
\text { DE JAIME RATÉS }\end{array}$ \\
\hline Onieva, Antonio Juan & Bolinaga, Josefina & Santacruz, Pascual \\
\hline MAGISTERIO ESPAÑOL & PRIMA LUCE & TIPOGRAFÍA SAN FRANCISCO \\
\hline Álvarez de Cánovas, Josefina & Villergas, José María & Buendía Soler, M. ${ }^{\text {a Esperanza Marina }}$ \\
\hline Calavia, Leonides Gonzalo & PASAJES & LIBRERÍA RELIGIOSA \\
\hline Fernández Ascarza, Victoriano & Pablo Romero, Juan José de & Padre Ruiz Amado \\
\hline Fernández Rodríguez, Antonio & DALMAU CARLES, PLA & Quintana, L. \\
\hline Jesús, Manuel del & Briones, José & SANCHEZ RODRIGO \\
\hline Oñate, M. ${ }^{a}$ del Pilar & Manzanares Beriain, Alejandro & Fernández Rodríguez, Antonio \\
\hline Ortiz Muñoz, Luis & Dalmáu Carles, José & Rodríguez Álvarez, Ángel \\
\hline Solana, Ezequiel & Franganilllo y Monge, Manuel & ESPAÑOLA \\
\hline HIJO DE RICARDO GONZÁLEZ & HIJOS DE SANTIAGO RODRÍGUEZ & García Sanchiz, Federico \\
\hline Fernández Rodríguez, Antonio & Arias, Manuel Antonio & EDITORIAL FET \\
\hline Hernández Ruiz, Santiago--- & Baldó, María & Muñiz Vigo, Acisclo \\
\hline Torres, Federico & Basabe, Enrique & HIJO DE PALUZIE \\
\hline LA EDUCACIÓN & Bolinaga, Josefina & Pascual de Sanjuán, Pilar \\
\hline Fernández Rodríguez, Antonio & Gil Muñiz, Alfredo & XALCO \\
\hline Herrero Pérez, José & Lizondo Gascueña, Julián & Mendoza, José María Guinea \\
\hline EDITORA NACIONAL & Manzanares Beriain, Alejandro & OLIMPO \\
\hline Torres, Federico & Onieva, Antonio Juan & Casassas, Cantó Enrique \\
\hline $\begin{array}{l}\text { IMPRENTA ELZEVIRIANA Y } \\
\text { LIBRERÍA CAMÍ }\end{array}$ & Ruiz García, Matilde & GRÁFICAS REUNIDAS \\
\hline Serrano, Leonor & Santiago Fuentes, Magdalena & Bohigas Gavilanes, Francisca \\
\hline
\end{tabular}

Fuente: elaboración propia.

\footnotetext{
"Librería de los Herederos de Hernando.

*** Su verdadero nombre era Luisa Torralba de Martí (por ser la esposa de Joaquín Martí) pero utilizó varios pseudónimos como Aurora Lista o Antonio R. del Castillo.

***** La información que se aporta es que ha sido editado por E.G.V., tratándose del editor Enrique Gutiérrez Villanueva.
} 
De un total de 109 manuales de lectura localizados desde 1959 hasta 1980, se han identificado 60 autores o equipos editoriales. En la década de los cincuenta han sido localizados un total de 40 (36,69\%) manuales de 29 autores diferentes, lo que supone que durante esta década aparecen casi el $48,3 \%$ de los autores, casi la mitad de ellos. En los años sesenta se han contabilizado $37(33,9 \%)$ manuales de 12 autores (20\%) y en los setenta aparecen $30(30 \%)$ títulos de 19 autores distintos $(31,7 \%)$.

Tabla 2. Libros de lectura y autores que publican por décadas, sobre un total de 109 libros y 60 autores

\begin{tabular}{|c|c|c|c|c|}
\cline { 2 - 5 } \multicolumn{1}{c|}{} & 109 Libros & \% Libros & 60 Autores & \% Autores \\
\hline $\mathbf{5 0 s}$ & $40 / 109$ & $36,69 \%$ & $29 / 60$ & $48,3 \%$ \\
\hline $60 \mathrm{~s}$ & $37 / 109$ & $33,9 \%$ & $12 / 60$ & $20 \%$ \\
\hline $70 \mathrm{~s}$ & $30 / 109$ & $30 \%$ & $19 / 60$ & $31,7 \%$ \\
\hline
\end{tabular}

Fuente: elaboración propia.

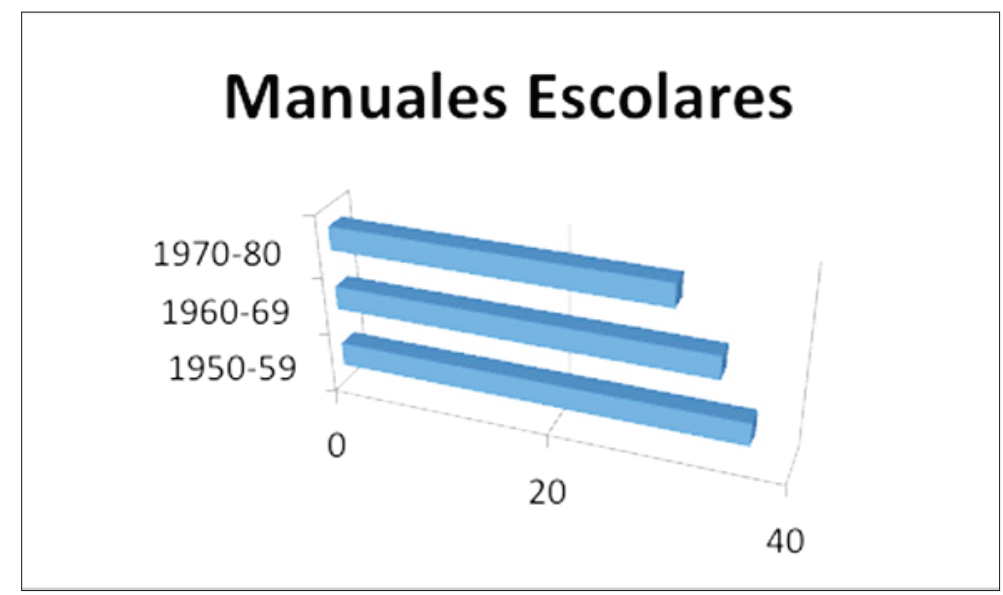

Fuente: elaboración propia

Gráfico 1. Libros de lecturas publicados por décadas.

Es posible observar en el gráfico que la edición de manuales de lectura durante las tres décadas va disminuyendo aunque de una forma lenta.

Lo mismo sucede, como podemos ver a continuación, con el número de autores contabilizados en cada una de las décadas estudiadas. Práctica- 
mente el 50\% de los autores que publican manuales escolares de lectura lo hicieron durante la década de los años cincuenta:

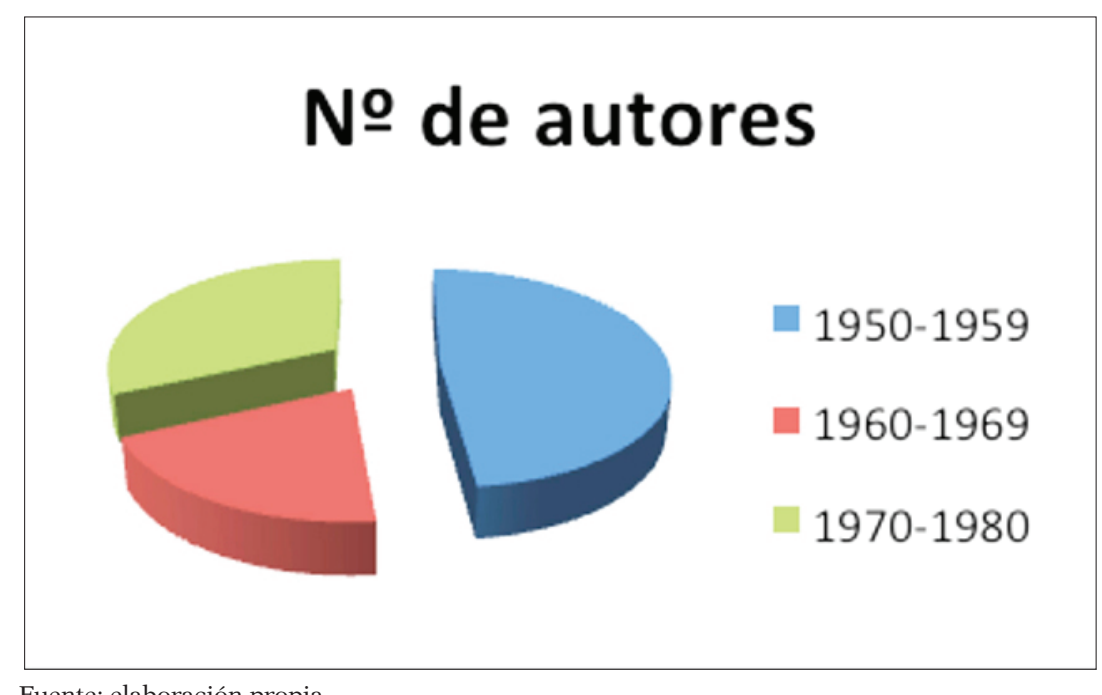

Fuente: elaboración propia

Gráfico 2. Autores de libros de lecturas por décadas

Se puede observar claramente qué autores publican en cada década estudiada. En los años cincuenta destacan Manuel García Tena o Federico Torres, productivos autores de libros de lectura. Muchos de ellos publican solo durante la década de los cincuenta. Sin embargo, algunos sobreviven hasta bien entrada la década de los sesenta como Agustín Serrano de Haro, Antonio Onieva, o Adolfo Mállo, los tres maestros e inspectores de Educación Primaria, o Josefina Bolinaga, poeta, colaboradora de Gente menuda ${ }^{33}$ y ganadora del Premio Nacional de Literatura. ${ }^{34}$ Es importante señalar que a todos estos autores les caracteriza la potencia emocional de los contenidos, textuales e icónicos, de sus manuales escolares.

${ }^{33}$ Gente Menuda fue un suplemento infantil del diario $A B C$, creado por Torcuato Luca de Tena y Álvarez Ossorio.

${ }^{34}$ Hemeroteca $A B C$. Véanse:

http://hemeroteca.abc.es/nav/Navigate.exe/hemeroteca/sevilla/abc.sevilla/1935/06/06/009.html; http://hemeroteca.abc.es/nav/Navigate.exe/hemeroteca/madrid/abc/1927/04/12/030.html y http://hemeroteca.abc.es/nav/Navigate.exe/hemeroteca/sevilla/abc.sevilla/1934/07/19/010.html (consultadas el 25-02-2015). 
El primer texto que se ha encontrado de Serrano de Haro data de 1953, el último de 1964, aunque sabemos, a través de consultas en distintas Bases de Datos ${ }^{35}$ especializadas en manuales escolares, que este autor publicó hasta la década de los ochenta. ${ }^{36}$ De Antonio Onieva se han encontrado libros de lectura desde 1953 hasta 1964, mientras que de Adolfo Maíllo y de Josefina Bolinaga aparecen sobre todo durante la década de los sesenta. Es importante señalar que, como era habitual en aquella época, dichos autores eran fieles a alguna editorial importante: Escuela Española, Afrodisio Aguado o Hijos de Santiago Rodríguez.

Se ha observado también como en la primera década estudiada finaliza la actividad de antiguas editoriales; tal es el caso de la editorial Hernando, pionera en la edición de textos escolares en España, fundada por Don Victoriano Hernando y Palacios en 1828. El último manual contabilizado de esta editorial es de 1955. Ocurre lo mismo con Seix y Barral, fundada en 1911 como empresa de artes gráficas, de la que se ha contabilizado el último manual en 1956. Esta editorial se incorporó al Grupo Planeta en 1982.

Sin embargo, varias de estas editoriales sobreviven también hasta los años sesenta, una de las más significativas es Escuela Española -anteriormente denominada Ezequiel Solana y Magisterio Español- de la que se han registrado textos desde 1953 hasta 1964. Ocurre lo mismo con Afrodísio Aguado, posteriormente Editorial Miñón, cuyo último libro contabilizado es de principios de los años sesenta. La editorial Dalmau, fundada en 1904, publica también manuales de lectura al menos hasta 1966.

Llaman la atención dos editoriales que publican prácticamente durante todo el periodo: Hijos de Santiago Rodríguez y Edelvives. De la primera de ellas se han encontrado manuales desde 1958 hasta 1978. Hijos de Santiago Rodríguez S.A., denominada originalmente «Santiago Rodríguez», fue fundada en 1850 junto con la casa editorial y el taller de impresión. Su logotipo, Minerva, diosa de la sabiduría, las artes y el pensamiento —símbolo del progreso intelectual—, y su lema «La escuela redime y civiliza», explican y resumen la filosofía empresarial que influyó en los negocios de su fundador,

\footnotetext{
35 Base de datos del Centro de Investigación MANES disponible en: http://servidormanes.uned.es/manes/consulta.html y catálogo en línea del Centro internacional de la Cultura Escolar (CEINCE) disponible en http://www.ceince.eu/.

${ }^{36}$ La 9. a edición a color del libro de lectura Hemos Visto al Señor se publicó en 1982. Un ejemplar se halla en la Biblioteca de Educación del Ministerio de Educación, Cultura y Deporte.
} 
Santiago Rodríguez. La editorial contó con los mejores autores e ilustradores del momento, el propio fundador escribió algunos de los primeros manuales que se publicaron, así como también lo hicieron algunos de sus descendientes. En esta editorial hemos identificado autores tan significativos como Josefina Bolinaga, Adolfo Maíllo, mencionados anteriormente o Begoña Bilbao.

De la editorial Edelvives han sido localizados un total de 10 manuales comprendidos entre 1951 y 1975 . Esta editorial fue fundada en 1889 por los Hermanos Maristas y llamada, en sus orígenes, FTD. En la década de los treinta cambió su nombre por el de Editorial Luis Vives. Aún hoy tiene una alta producción y una importancia significativa en el mercado de las editoriales escolares españolas. ${ }^{37}$

En la década de los setenta, con la llegada de la LGE surgieron nuevos autores y, sobre todo, nuevas editoriales que alcanzarían, posteriormente, gran importancia y un considerable volumen editorial. Especialmente la Editorial Anaya y la Editorial Santillana, fundadas en 1959 y 1960 respectivamente, muestran manuales localizados desde finales de los años sesenta o principios de los años setenta. De la Editorial Anaya hemos localizado manuales de 1968 hasta 1980 y de la editorial Santillana desde 1973 hasta 1980.

Para el análisis de los contenidos de los libros de lectura, con el apoyo del examen cuantitativo inicial, se han seleccionado un total de 19 libros de lectura; diez de los años cincuenta y sesenta y nueve de la década de los años setenta (ver Tabla 3). Es necesario aclarar que se trata de libros de lectura de Enseñanza Primaria, destinados a niños y niñas que ya sabían leer; es decir, con un nivel mínimo de comprensión lectora. Con el fin de asegurar la representatividad de la muestra y su uso en el aula, se han seleccionado aquellos libros de lectura de autores relevantes y de las mencionadas editoriales significativas.

\footnotetext{
${ }^{37}$ Sobre las editoriales y el mundo de la edición de libros de texto en estos años, se puede consultar Miguel Beas Miranda, «La Asociación Nacional de Editores de Libros de Texto: desde la Transición hasta el siglo XXI: Entrevista a Don Mauricio Santos», Historia de la Educación: Revista interuniversitaria, 19 (2000): 141-178, Soledad Montes Moreno, «El boom de la edición escolar: producción, comercio y consumo de libros de enseñanza», en Historia ilustrada del libro escolar en España: de la posguerra a la reforma educativa, coord. Agustín Escolano Benito (Madrid: Fundación German Sánchez Ruiperez, 1997), 73-102, y Antonio Viñao, "El libro escolar», en Historia de la edición en España 1939-1975, dir. Jesús A. Martínez Martín (Madrid: Marcial Pons Historia, 2015), 681-698.
} 
Tabla 3. Manuales Seleccionados

\begin{tabular}{|c|c|}
\hline Años & Libros de lectura \\
\hline 1957-1969 & 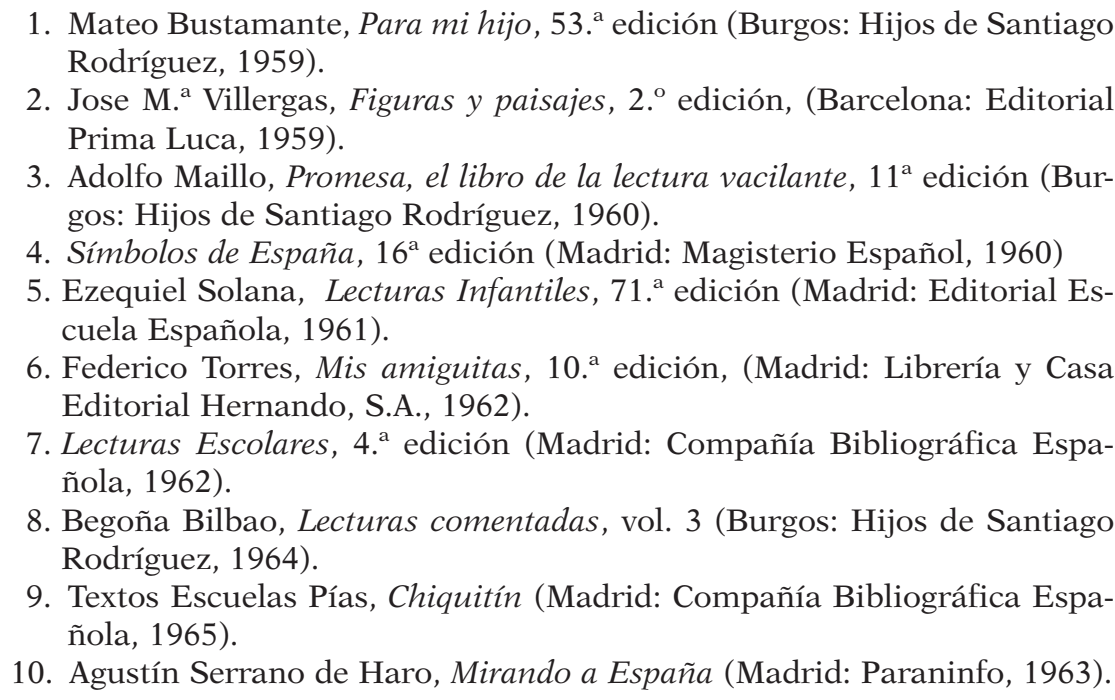 \\
\hline $1970-1975$ & $\begin{array}{l}\text { 1. Wenceslao Ezquerra, Nuevas letras, (sin editorial, 1972). } \\
\text { 2. Enséñame. Cartilla } 1 \text { (Zaragoza: Edelvives, 1973). } \\
\text { 3. Manuel Sanjuán y José Vázquez, Ventanal, (Madrid: Escuela Española, } \\
\text { 1974). } \\
\text { 4. Dora Quecero y Ángeles Bachiller, Quiero leer y escribir, 4. }{ }^{\circ} \text {, (Burgos: } \\
\text { Santiago Rodríguez, 1975). } \\
\text { 5. Dora Quecedo y Angeles Bachiller, Quiero leer y escribir, 8. a edición (Bur- } \\
\text { gos: Editorial Santiago Rodríguez, 1975). } \\
\text { 6. Ya pasé (Zaragoza: Edelvives, 1975). } \\
\text { 7. Senda. Libro de lectura, (Madrid: Santillana, 1976). } \\
\text { 8. Mundo Nuevo, (Madrid: Ediciones Anaya, 1976). } \\
\text { 9. Manuel Antonio Arias, Amiguitos. Segunda Cartilla, 50. a edición (Burgos: } \\
\text { Santiago Rodríguez S.A., 1978). }\end{array}$ \\
\hline
\end{tabular}

Fuente: elaboración propia.

Conviene aclarar las fases de la dictadura que se han tomado como base para la organización temporal del contexto. Aunque nos guiamos por los estudios sobre la periodización del franquismo, ${ }^{38}$ se ha optado por enfocar la clasificación temporal en función de lo acontecido en el terreno educativo. Se considera que el primer franquismo, desde esta perspectiva, puede abar-

38 Juan Manuel Fernández Soria, Educación, socialización y legitimación política (España 1931-1970) (Valencia: Tirant lo Banch, 1998), 101-125. 
car desde el final de la Guerra Civil hasta el año 1945, cuando se promulga la ley de Enseñanza Primaria, se confirma el nacional-catolicismo, se promulga el principio de subsidiariedad en Educación Primaria y se abandonan el dominio de la Falange y sus aspiraciones totalitarias.

El segundo franquismo abarcaría el período fuerte del nacional-catolicismo, desde 1945 hasta el primer gobierno tecnócrata de 1957, pasando por la aprobación de los primeros cuestionarios nacionales en 1953 y la creación de la Sección de Pedagogía de la Universidad de Barcelona en 1955, año en que comienzan a celebrarse los Congresos Nacionales de Pedagogía de la Sociedad Española de Pedagogía.

El tardofranquismo ocuparía los años de los tecnócratas desde la aprobación del Plan de Estabilización de 1959, «aceptado a regañadientes por Franco" ${ }^{39}$ hasta el final del régimen dictatorial. No obstante, con el fin de ubicar con precisión los libros de lectura seleccionados, y a tenor del resultado de la investigación, se ha procedido a dividir el tardofranquismo en dos sub-etapas. La primera de ellas comprende los años que vieron el nacimiento del Centro de Orientación y Documentación Didáctica de Enseñanza Primaria $^{40}$ (CEDODEP) en 1958, de los segundos Cuestionarios Nacionales de Enseñanza Primaria de 1965, de los Programas de 1968 y del Libro Blanco de 1969. La segunda sub-etapa está marcada por la LGE de 1970 y todo lo que a raíz de su aprobación fue legislado.

\section{LOS LIBROS DE LECTURA EN EL PRIMER TARDOFRANQUISMO (1959-1969)}

Una disposición legal de $1955^{41}$ precisaba ya unos criterios de aprobación de los libros sometidos a examen que implicaban toda una concepción del manual escolar diferente a la anterior: adaptación a los intereses infantiles, empleo de técnicas específicas de redacción, adecuación a determinados métodos (por ejemplo, de enseñanza simultánea de la lectura

\footnotetext{
${ }^{39}$ Charles Powell, España en democracia, 1975-2000. Las claves de la profunda transformación de España (Barcelona: Plaza y Janés, 2001), 24.

${ }^{40}$ Decreto de 25 de abril de 1958 por el que sea crea el Centro de Documentación y Orientación Didáctica de Enseñanza Primaria «dedicado al perfeccionamiento técnico de este grado de la enseñanza». Boletín Oficial del Estado 116 (15 de mayo de 1958), 882.

${ }^{41}$ Decreto de 22 de septiembre de 1955, Boletín Oficial del Estado número (17 de octubre de 1955), 6281-6283.
} 
y escritura), uso de vocabulario común y especializado, exposición clara y lógica, cualidades estéticas, estilos literarios descriptivos, narrativos y dialogados. ${ }^{42}$ El profesor de Pedagogía de la Universidad de Madrid y autor de numerosos libros de texto, Victorino Arroyo, detallaba a fondo los diferentes tipos de libros de lectura, explicando que su finalidad esencial era «la de servir de motivación para despertar en los escolares un deseo de leer». ${ }^{43}$ Sin embargo, los libros de lectura en esta época estaban claramente destinados al adoctrinamiento ideológico. ${ }^{44}$ Todavía se hacía un uso político explícito de la lectura y la lectura se distinguía poco de la memorización y de la aceptación pasiva de los mensajes subyacentes. ${ }^{45}$

Se han seleccionado diez libros de lectura relevantes de la década de los sesenta guiándonos por los criterios de representatividad de la autoría (popularidad y autoridad del autor), del número de ediciones y del prestigio de la editorial, para examinar el efecto que tuvieron los nuevos pasos hacia un enfoque más didáctico de la enseñanza.

En esta década todavía se mantienen autores y editoriales que tuvieron fuerte relevancia en las primeras décadas del franquismo. Se trata de autores cuyos manuales tenían una fuerte impronta personal y carga emocional. No obstante, hacia finales de los años cincuenta comenzó la convivencia con una nueva tendencia emocionalmente más aséptica y pedagógicamente más didáctica. En este periodo empezaron a aparecer prolegómenos en los libros con diferencias significativas con los anteriores. Si hasta mediados de los cincuenta los autores de los manuales escolares no escatimaban alusiones a los sentimientos y a las emociones en sus textos introductorios al corpus instructivo de sus obras, éstas empezaron a convivir con otras de carácter más pedagógico y didáctico hacia finales de la misma década.

Tras la creación del CEDODEP en 1958 se elaboraron las primeras instrucciones para la redacción y selección de textos, y en 1960 se fijaron las

\footnotetext{
42 Agustín Escolano Benito, "Sobre la construcción histórica de la manualística en España», Revista Educación y Pedagogía, XIII (29-30), (2001): 20.

43 Victorino Arroyo del Castillo, «El libro de lectura: tipos y finalidades», Vida Escolar, 89-90 (1967): 34.

${ }^{44}$ En este sentido, el caso de España no es único. Ver por ejemplo, Katharine D. Kennedy, «A Nation's Readers: Cultural Integration and the Schoolbook Canon in Wilhelmine Germany», Paedagogica Historica: International Journal of the History of Education, 33 (2), (1997): 459-480.

45 Antonio Viñao, «La alfabetización en España: un proceso cambiante de un mundo multiforme», Efora, 3 (marzo, 2009): 5-19, consultado el 5 de junio de 2015. URL: http://www.usal.es/efora. El autor alude a las prácticas y usos de la lectura y la escritura.
} 
características que debían reunir los libros escolares para ser aprobados. La mayor parte de estas innovaciones quedaron registradas en las publicaciones que editó el centro y en su labor de difusión fundamentalmente a través de la revista Vida Escolar, que llegaba mensualmente a todas las escuelas del país. Por ejemplo, en el número 89-90 de 1967, Juan Navarro Higuera, inspector de Enseñanza Primaria, publicó «La ilustración de los manuales escolares» donde analizó las ventajas del uso de los recursos iconográficos.

Aun así, a principio de los años sesenta, se encuentran manuales de editoriales y autores importantes que apelan al contenido emocional como base de su obra. ${ }^{46}$ En 1961, Ezequiel Solana, en un libro de la editorial Escuela Española comienza así el prefacio:

Con el título de LECTURAS INFANTILES he dispuesto una serie de relatos e historietas morales, con asuntos sencillos, lenguaje conciso y claro, que terminan como una máxima o precepto moral, propio para formar el corazón e inspirar en los niños puros y delicados sentimientos. ${ }^{47}$

En el prólogo de Mirando a España de Agustín Serrano de Haro, editado en $1963,{ }^{48}$ aparecen sustantivos y adjetivos como bellas, hermosas, maravillas, espléndidas, palpitaciones, todos ellos referidos bien a las palabras y a la lectura, o bien a la patria. El autor realiza una personificación del libro comparándolo con "el verdadero amigo» en un intento claro de despertar distintos sentimientos en el lector.

Sin embargo, estos fines educativos, claramente adoctrinadores en sus intenciones, empiezan a coexistir con otros que incorporan objetivos didácticos y pedagógicos en el libro de lectura que apelan a los métodos de enseñar a leer. El fin de las lecturas que contienen estos textos ya no es solo sensibilizar al alumno hacia la patria o hacia Dios. En la undécima edición de la obra Promesa, el libro de la lectura vacilante, de Hijos de Santiago Ro-

\footnotetext{
${ }^{46}$ El maestro Antonio Correa Acosta nos revela en sus memorias publicadas con el título A la luz de la razón. Memoria de un maestro de principios de los 60, editado por Amelia Correa Ramón y Miguel Beas Miranda (Granada: Universidad de Granada, 2014), 117-118, que los libros empleados para la lectura en el grupo escolar Pedro Alonso Niño, en Moguer, Huelva, fueron los manuales de las décadas anteriores: las cartillas Amiguitos de Antonio Arias, El Parvulito de Antonio Álvarez Pérez, y Hemos Visto al Señor de Agustín Serrano de Haro.

47 Ezequiel Solana, Lecturas Infantiles, $71 .^{\text {a }}$ edición (Madrid: Escuela Española, 1961), 4.

${ }^{48}$ El prólogo lo firma Leónides Gonzalo Calavia, Inspector Central de Enseñanza Primaria.
} 
dríguez, el autor indica explícitamente que la intención del texto es perfeccionar los mecanismos de la lectura infantil poniendo al niño en contacto sistemático con sílabas y palabras cuyas dificultades fonéticas impiden al escolar el manejo ágil de su propio idioma. ${ }^{49}$ Aparecen sustantivos y adjetivos con menos carga emocional y de una condición más técnico-educativa: mecanismos, sistemático, fonema, sílabas, idioma.

Begoña Bilbao, en su obra de la misma editorial que la anterior, publicada en 1964, advierte al maestro que saber leer es saber estudiar, y que saber estudiar comporta (entre otras cosas) «afirmar la personalidad, despertando el espíritu crítico, documentándose aquí y allá para llegar a elaborar ideas y opiniones propias». ${ }^{50}$ Teniendo en cuenta que el espíritu crítico supone la capacidad del ser humano de cuestionar los principios, valores y normas que se le ofrecen en el entorno en el que se desenvuelve, para que sea capaz de formarse un criterio propio que le permita tomar sus propias decisiones en las distintas situaciones que se le presentan, este ejemplo es clarificador para analizar que ciertamente, en este periodo, empiezan a aparecer ciertas novedades, en algunos casos, notorias e importantes en la conformación del ciudadano y de la socialización política.

Este mismo equilibrio entre continuidades y rupturas aparece cuando entramos a analizar el corpus instructivo del libro. Aunque empieza a debilitarse la carga emocional de los contenidos, siguen apareciendo dos grandes temas en torno a los que giran el mundo emocional y la socialización política: la patria y la religión. En muchos de los manuales de esta época encontramos todavía capítulos dedicados a España, a la bandera o al himno nacional. En 1959, autores como José María Villergas, inspector de Primera Enseñanza, añade como última lectura de su manual «Los emblemas de la Patria», que sirve de ejemplo para mostrar la transmisión de sentimientos de orgullo nacional, pero también para detectar las instrucciones didácticas precisas para llevar a cabo y participar en determinados actos socio-políticos, «con emoción y con entusiasmo». En esta lectura encontramos frases como "grandeza de España», "orgullo de ser hijos de esta nación» e instrucciones precisas sobre como cantar los himnos: «lo hacemos con fe, con emoción y con entusiasmo». ${ }^{51}$

\footnotetext{
49 Adolfo Maillo, Promesa, el libro de la lectura vacilante, 11. ${ }^{\text {a }}$ edición (Burgos: Hijos de Santiago Rodríguez, 1960), 3.

${ }^{50}$ Begoña Bilbao, Lecturas comentadas, vol. 3 (Burgos: Hijos de Santiago Rodríguez, 1964), 3.

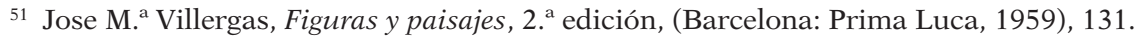


En el libro Promesa. El libro de lectura vacilante, ${ }^{52}$ el inspector de Enseñanza Primaria Adolfo Maíllo, todavía añade este tipo de instrucción emocional en las actividades relacionadas con la lectura de su libro, aunque, como se ha señalado anteriormente, el prólogo contiene instrucciones didácticas sobre la lectura.

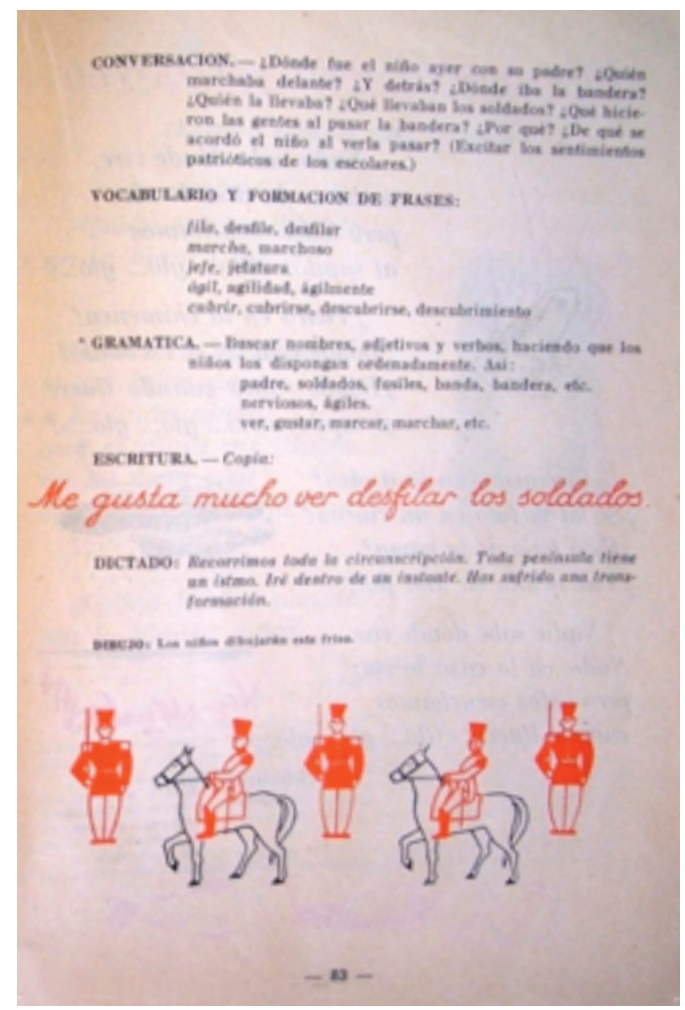

Figura 1. Adolfo Maíllo, Promesa. Libro de lectura vacilante, 11. a edición (Burgos: Hijos de Santiago Rodríguez, 1960), 83.

El análisis de los índices de los libros es válido para comprobar que, aunque los manuales presentan temas diversos, todos ellos contienen también capítulos o lecturas con temas religiosos, contenidos expuestos a excitar emociones como el amor, el miedo o la culpa. Además de las cuantiosas lecturas dedicadas a diferentes santos y mártires, seguidamente se indi-

52 Analizamos la 11. a edición. La primera es de 1951. El libro perdura durante casi una década. 
can, como ejemplo, algunos títulos de estas lecturas: «Sobre la grandeza de Dios», «La Virgen María estuvo en España», «Pascua de Resurrección». En algunos casos, estos contenidos poseen toda la potencia emocional de los textos de las décadas anteriores. El libro de Ezequiel Solana, publicado por Escuela Española en 1961 comienza de la siguiente forma:

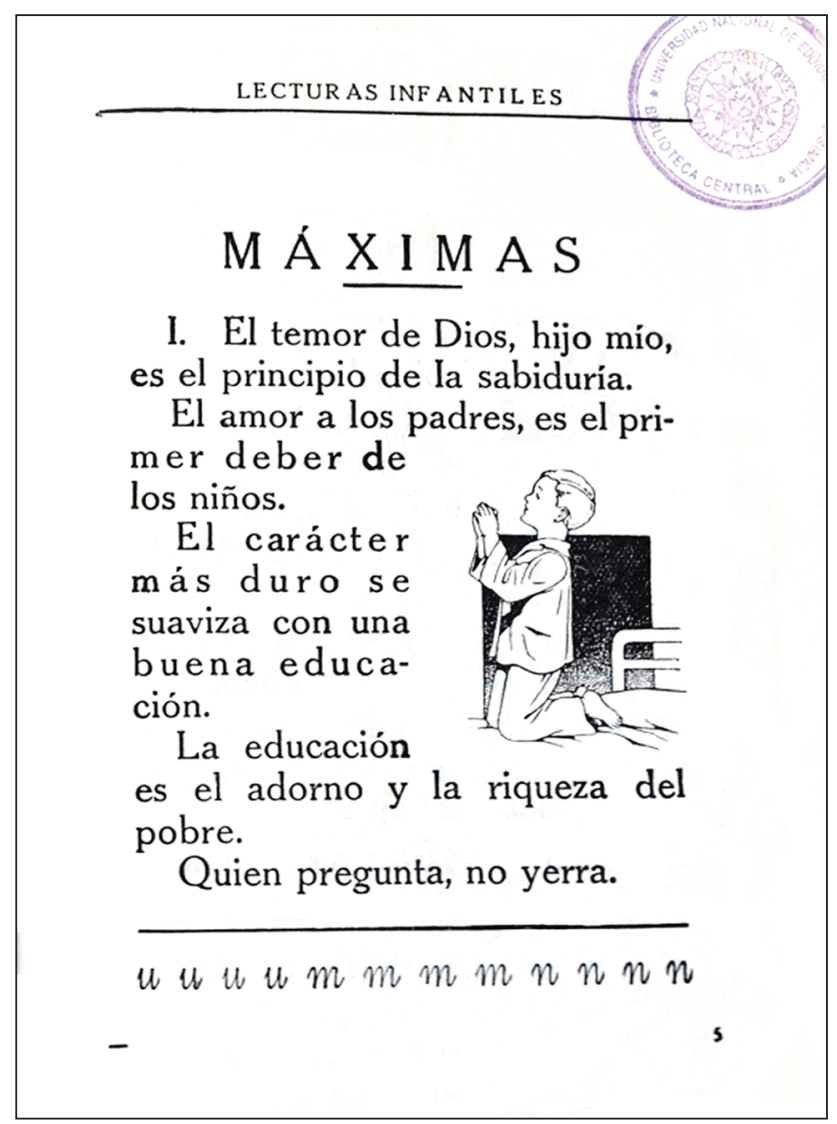

Figura 2. Ezequiel Solana, Lecturas Infantiles, 71. a edición (Madrid: Editorial Escuela Española, 1961), 5.

Aparecen términos como temor, amor, deber, con una fuerte carga emocional. Al final de la lección, en un segundo plano, se leen las letras que se debían aprender: la «u», la «m» y la «n». Todavía en ocasiones, y como ocurrió durante las décadas de los cuarenta y cincuenta, la enseñanza de la 
lectura aparece como un objetivo secundario a otras enseñanzas de carácter superior como la moral, la ética y la política, que enseñan que tipo de ciudadano se debía ser.

Federico Torres es otro de los prolíficos autores de libros de lectura a principios de la década de los sesenta que mantiene la continuidad de los esquemas de transmisión emocional en cuanto a los aspectos políticos y sociales se refiere. En la décima edición de Mis amiguitas, publicado en 1962 pero originalmente en los años cuarenta, todavía podemos leer:

La Patria es el segundo de nuestros grandes amores. Dios es el primero, la Patria, después. Amemos la tierra donde nos cupo la honra de nacer, como amamos el hogar en que vivimos, como amamos a nuestros padres y a nuestros hermanos..$^{53}$

Hasta cuatro veces relaciona el verbo amar con la patria, la tierra o el hogar. Se observa que el contenido emocional se mantuvo explícito y dirigido hacia una socialización política determinada y condicionada por la ideología nacional católica.

A pesar de estas continuidades, la transmisión de este tipo de contenidos - propios del nacional-catolicismo- disminuye considerablemente su carga afectiva y aparecen de una forma mucho más sutil y tenue. Así sucede en el libro de Adolfo Maíllo ya citado, Promesa, el libro de la lectura vacilante, en el que tanto los contenidos referidos a la patria como los referidos a la religión aparecen entre otros mucho más asépticos.

La complejidad del proceso de redacción, edición y publicación del libro de texto se hace evidente cuando analizamos la décima edición de la segunda parte del Silabario Chiquitín, publicado por la Compañía Bibliográfica Española en 1965, con la nota de aviso de tratarse de una obra «aprobada por el Ministerio de Educación Nacional para servir de texto en las escuelas, según lo dispuesto en la Orden ministerial de 30 de junio de 1958»; es decir, según lo dispuesto siete años antes. En la introducción los autores informan de su propósito de ofrecer al parvulista su método de lectura, «basado en los procedimientos más modernos contrastados por una larga experiencia», y de cómo son dos «los sistemas preferidos en la composición de CHIQUITIN:

\footnotetext{
${ }^{53}$ Federico Torres, Mis amiguitas, 10. a edición (Madrid: Librería y Casa Editorial Hernando, S.A., 1962), 54 y 55.
} 
el ideológico y el fonomímico». En el primero, dicen, se parte de la palabra-tipo que responde al dibujo de la lección, y de esta forma «se inicia a los niños en temas llenos de vida y de sentido. Luego vendrá la descomposición en sílabas y letras». ${ }^{54}$ El sistema ideológico incluye así la idea de amor a la patria, confirmando que el libro de lectura, hasta bien entrados los años sesenta, continuó siendo un manual de formación socio-política reforzada por una fuerte orientación emocional. En esta misma introducción se observa que, aunque los autores comienzan hablando de los métodos modernos de enseñanza de la lectura, concluyen indicando al maestro que el método funcionará mejor si se «hace niño como los niños y logra derramar en sus puros corazones mieles de cariño». ${ }^{55}$

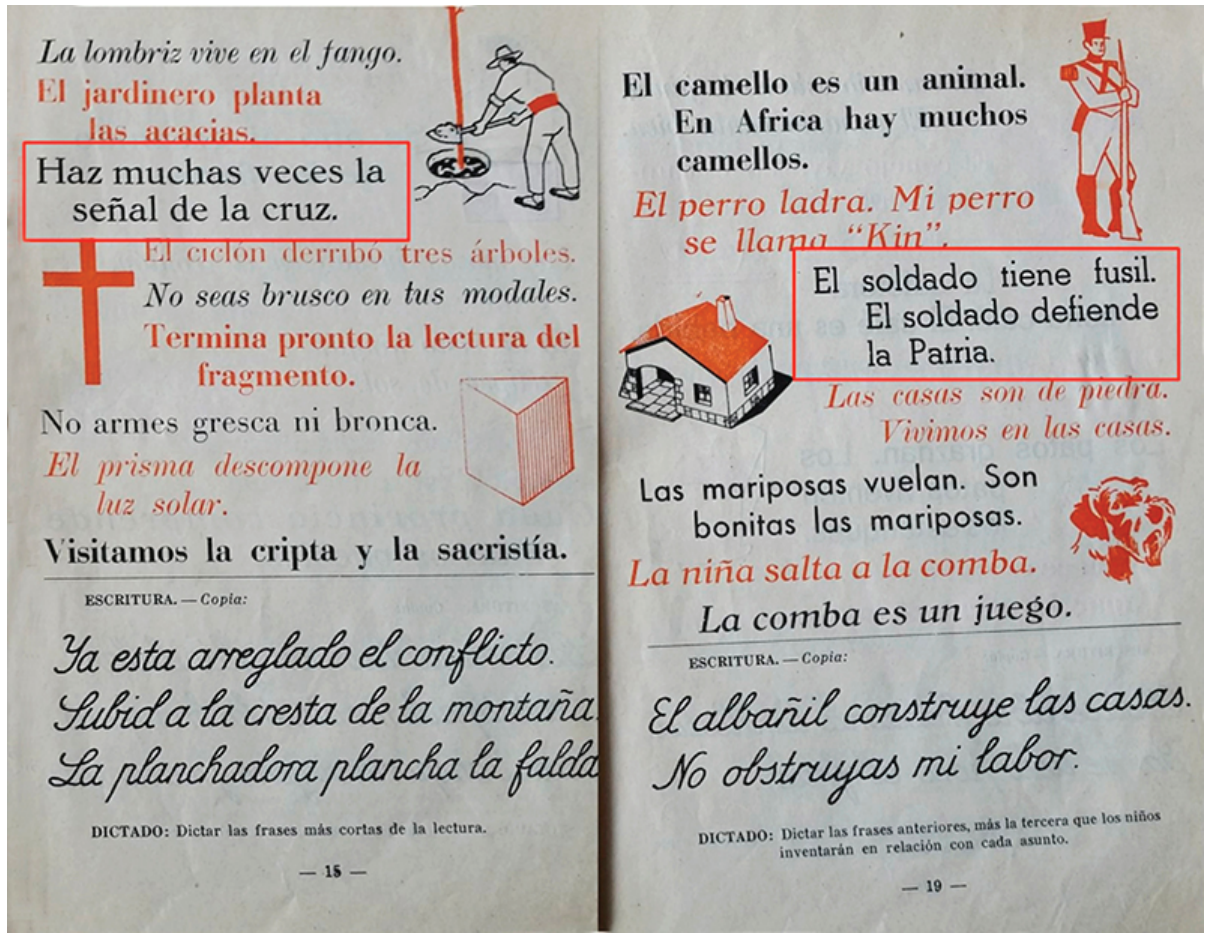

Figura 3. Adolfo Maíllo, Promesa. Libro de lectura vacilante, $11 .^{\text {a }}$ edición (Burgos: Hijos de Santiago Rodríguez, 1960), 15 y $19 .{ }^{56}$

\footnotetext{
54 Textos Escuelas Pías, Chiquitín (Madrid: Compañía Bibliográfica Española, 1965), 3.

55 Textos Escuelas Pías, Chiquitín, 3.

${ }^{56}$ Los cuadrados rojos son nuestros.
} 
Fue en los Cuestionarios de 1965 donde se expresó con mayor claridad y énfasis el espíritu renovador que comenzaba a instalarse en el contexto educativo: «La Escuela española, deseosa siempre de actualizarse y establecer positivas correlaciones con los avances científicos, psicológicos, pedagógicos y sociales renueva hoy el contenido de sus Cuestıonarios de Enseñanza Primaria». ${ }^{57}$ A propósito del proceso de la enseñanza de la lectura se enumeran las siguientes características didácticas:

«proceso lector, En este apartado se señalan para cada curso de escolaridad las principales características que debe tener una didáctica de la lectura indicando solamente aquellas de mayor relieve y consideración:
a) Tradición de fonemas de los signos correspondientes
b) Comprensión del significado de palabras y frases
c) Comprensión de ideas fundamentales en párrafos y textos
d) Correcta expresión oral con matices adecuados
e) Comprensi6n de ideas básicas y fundamentales de un texto con finalidad de estudio.
f) Comprensión del estilo del texto y de la intencionalidad del autor». ${ }^{58}$

\section{LA PRESENCIA DE CONTENIDO EMOCIONAL EN EL SEGUNDO TARDOFRANQUISMO (1970-1975)}

El sistema educativo nacional asume actualmente tareas y responsabilidades de una magnitud sin precedentes. Ahora debe proporcionar oportunidades educativas a la totalidad de la población para dar así plena efectividad al derecho de toda persona humana a la educación y ha de atender a la preparación especializada del gran número y diversidad de profesionales que requiere la sociedad moderna. ${ }^{59}$

Con estas palabras comienza la disposición general de la Jefatura del Estado por la que se dicta la LGE de 1970.

A finales de los años sesenta, España empezó a experimentar grandes cambios sociales y económicos. Como afirma Manuel de Puelles, se comen-

\footnotetext{
57 «ORDEN de 8 de julio de 1965 por la que se aprueban los cuestionarios que han de regir todas las actividades didácticas en las Escuelas Primarias». Boletín Oficial del Estado, 229 (24 de septiembre de 1965), 13006.

${ }^{58}$ Cuestionarios de 1965, Boletín Oficial del Estado, 229 (24 de septiembre de 1965), 13009.

${ }^{59}$ Boletín Oficial del Estado, 187 (6 de agosto de 1970), 12525-12546.
} 
zó a producir el tránsito de una sociedad tradicional a una sociedad de asalariados y consumidores. ${ }^{60} \mathrm{El}$ sistema educativo se mostraba incapaz de dar respuesta a las necesidades de una sociedad española, que aunque sumergida en un intenso proceso de cambio seguía sujeta a las viejas leyes del franquismo. En este contexto surgió la LGE de 1970 que, sin llegar a abordar el problema político que en ese momento padecía España, reformó el sistema educativo contando con dos recursos fundamentales: buenos técnicos e invirtiendo más fondos económicos. ${ }^{61}$ La LGE fue sin duda un importante intento de modernización del sistema educativo español y de comienzo de la democratización de la educación. ${ }^{62}$

Este cambio en la política educativa, unido a las modernas contribuciones de la psicopedagogía, de la didáctica y de la moderna tecnología se dejó notar también en la producción de los manuales escolares. El tradicionalismo pedagógico era incompatible con la dinámica de industrialización que iniciaba el país y que exigía una nueva escuela más acorde con las corrientes dominantes en los países en desarrollo.

La historia de los manuales de enseñanza y en general de los equipamientos y materiales didácticos inició un ciclo nuevo a mediados de los sesenta, pero fueron la LGE de 1970 y las nuevas editoriales las que promovieron ese tímido cambio de rumbo al enfatizar el desarrollo de los nuevos modelos de libros de trabajo y de consulta, y los materiales de apoyo.63 Todo ello incidió en los manuales escolares, caracterizados en esta época por presentar una serie de novedades tanto en su materialidad, como en sus recursos didácticos y contenidos. El mensaje redactado al maestro en el libro Mundo Nuevo de la Editorial Anaya comienza de la siguiente manera:

Los aspectos más instrumentales del lenguaje (lectura y escritura en la primera etapa) precisarán un tratamiento específico y un horario propio [...] Así se expresan las Nuevas Orientaciones para la Educación General Básica, y a esta exigencia pretende amoldarse el presente libro? ${ }^{64}$

\footnotetext{
${ }^{60}$ Manuel de Puelles, Política y educación en la España contemporánea (Madrid: UNED, 2010), 111.

${ }^{61}$ de Puelles, Política y educación, 111.

${ }^{62}$ Cecilia Cristina Milito Barone y Tamar Groves, «¿Modernización o democratización? La construcción de un nuevo sistema educativo entre el tardofranquismo y la democracia», Bordón, 65 (4), (2003): 135-148.

${ }^{63}$ Agustín Escolano Benito, «Discurso ideológico, modernización técnica y pedagogía crítica durante el franquismo", Historia de la Educación, 8 (1989): 7-27.

${ }^{64}$ Mundo Nuevo (Madrid: Ediciones Anaya, 1976).
} 
A pesar de estas innovaciones en el contexto educativo, los manuales escolares y, concretamente los libros destinados a la enseñanza de la lectura, presentaban todavía algunas reminiscencias de las décadas anteriores del franquismo, más en el fondo que en la forma y especialmente en cuanto a los contenidos políticos y religiosos se refiere. Sin embargo, su presentación y transmisión comenzó a ser mucho más sutil y la manipulación emocional más tenue y ligera.

Este tipo de contenidos que se mantienen del franquismo más adoctrinador pretenden mostrar al alumno el sentido de la patria aunque, cómo hemos dicho, aparecen de forma más etérea y ligera, especialmente en cuanto a su carácter emocional, que prácticamente desaparece. Las alusiones a estos contenidos se limitan a expresiones como «yo soy español», «nací en España» o a palabras sueltas que acompañan a una imagen monosémica con un significado único y concreto: «crucifijo», «altar» o «mapa».

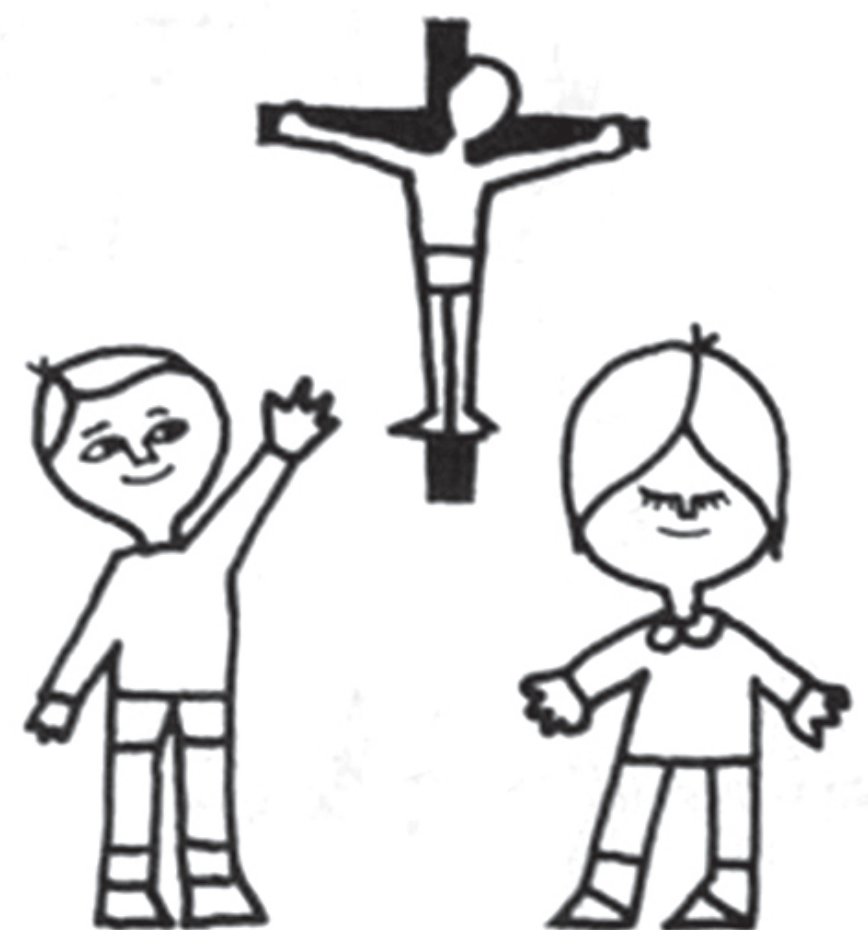

Figura 4. Dora Quecero y Ángeles Bachiller, Quiero leer y escribir, $4 .^{\circ}$ (Burgos: Santiago Rodríguez, 1975). 
En raras ocasiones encontramos textos donde se afirma la grandeza de España. Uno de ellos es un manual de Santillana editado en 1976 en el que, bajo el título de "Alabanza de España», encontramos reminiscencias del nacional-catolicismo anterior en afirmaciones como «la Patria es el Paraíso de Dios». Incluso en un intento de provocar el orgullo de ser español encontramos la siguiente afirmación: «España, en efecto, parece una síntesis del mundo: todas las cosas buenas y deseables están contenidas en la Península Ibérica». ${ }^{65}$ Se describe a España con adjetivos como «generosa», «atrevida» $\mathrm{y}$ «esforzada» en la batalla.

Ocurre lo mismo con los contenidos religiosos. A modo de ejemplo, en el manual de la editorial Santiago Rodríguez, de 1975, encontramos imágenes en la que se muestra el gesto amable y sonriente de los niños al señalar el símbolo religioso.

\section{El nuevo diseño de los libros de lectura en la década de los setenta}

La primera novedad que descubrimos al examinar los libros escolares del segundo tardofranquismo es el cambio en su materialidad, en su arquitectura y estética. Los manuales comenzaron a adoptar distintas formas y tamaños como, por ejemplo, el apaisado.

Comenzó a supeditarse el doble criterio estético y técnico al criterio didáctico, para facilitar la comprensión y la asimilación de la información. ${ }^{66}$ Es obvio que los libros de texto tradicionalmente utilizan dos códigos: el verbal y el icónico. Aunque el lenguaje icónico requiere de un análisis y una lectura en un sentido diferente al del lenguaje verbal ${ }^{67}$, son muchos los trabajos que analizan el uso y la didáctica de la imagen en el contexto escolar y, más concretamente, en los textos escolares. ${ }^{68}$ Pero es en esta época cuando varió

\footnotetext{
${ }^{65}$ Senda. Libro de lectura (Madrid: Santillana, 1976), 15-16.

${ }^{66}$ María Paz Prendes, «El diseño y la producción de manuales escolares», en Tecnologías para la educación: diseño, producción y evaluación de medios para la formación docente, coord. Jesús Salinas Ibáñez, Julio Cabero-Almenara y José Ignacio Aguaded Gómez (Madrid: Alianza Editorial, 2004), 9.

${ }^{67}$ María Paz Prendes, «La imágenes en los libros de texto», Comunicación y pedagogía: Nuevas tecnologías y recursos didácticos, 151(1998): 101.

${ }^{68}$ Ver Valeriano Bozal, «Las imágenes de la enseñanza. La enseñanza de la imagen», Revista de Educación, 296 (1991): 217-243; Carmen Benso Calvo y M. ${ }^{a}$ del Carmen Pereira Domínguez, «El proceso de incorporación de la imagen en los manuales escolares de urbanidad. Análisis de modelos», en Image et transmission des savoirs dans les mondes hispaniques et hispano-américains, dir. Jean Luis Guereña (Tours: Presses Universitaires François-Rabelais. 2006), 393-414; Ana María Badanelli Rubio, «Aproxi-
} 
de una forma significativa el número de ilustraciones que contenían. En el caso de los libros de lectura, la frecuencia de las ilustraciones por página aumentó considerablemente. Hay que tener en cuenta que la ilustración es un recurso importante para provocar emociones y sentimientos. En esta década, en parte por el abaratamiento de las técnicas de impresión y también por las nuevas tendencias pedagógicas, aumentaron la calidad de las imágenes y la variedad en la naturaleza de la ilustración: fotos, dibujos o gráficos. El uso del color comenzó a ser usual y mucho más frecuente que en la época anterior. Sin embargo, en esta época se simplificaron las imágenes porque se comenzaron a relacionar con el mundo infantil y se alejaron del mundo adulto. Anteriormente las imágenes eran más complejas en su composición (más número de personajes, la interacción entre ellos y el contexto, etc.) y polisémicas en cuanto a las posibles interpretaciones. En esta época las imágenes comienzan a ser más simples en su composición y, por tanto, más fáciles de descodificar, muchas acompañan al texto, a la palabra o al fonema y tienen un significado único e inequívoco. Es necesario tener en cuenta el receptor al que van destinadas estas imágenes, y que en sus procesos de percepción y comprensión intervienen tanto la influencia del medio cultural y educativo - inferencias contextuales-, como los relativos a la maduración intelectual del sujeto, ${ }^{69}$ en este caso, los alumnos de primaria.

El progreso en los métodos didácticos y pedagógicos se unió a la mejora técnica del libro de lectura como producto editorial. Este giro reforzó los objetivos pedagógicos de la enseñanza de la lectura y se distanció del énfasis propio del régimen político en los contenidos socio-emocionales. Así lo indican también los autores que abandonan progresivamente las alusiones a los aspectos emotivos y adoctrinadores en sus prólogos. Un ejemplo claro

mación a un método de lectura e interpretación de imágenes en los manuales escolares», en Etnohistoria de la escuela. XII Coloquio Nacional de Historia de la Educación, coords. Alfredo Jiménez Eguizábal et al. (Burgos: Universidad de Burgos, 2003), 333-342, e Ilustraciones en los manuales escolares (España 1900-1970). Tesis doctoral (UNED, 2003); M. Pilar Colás Bravo «El libro de texto y las ilustraciones: enfoques y perspectivas en la investigación educativa», Enseñanza \& Teaching: Revista interuniversitaria de didáctica, 7 (1989): 41-50; M. Pilar Colás Bravo y M. ${ }^{a}$ Isabel Corts Giner, «Las imágenes en los textos escolares españoles de principios de siglo», Revista de Ciencias de la Educación, 141 (1990): 41-49; Juan Monge Miguel, «Ensayo de estudio de la lecturabilidad icónica en ilustraciones escolares», Revista de Ciencias de la Educación, 11 (51) (1992): 459-466; M. ${ }^{a}$ Isabel Martín Requero, Iconografía y Educación. La imagen en los textos escolares en la escuela franquista (1939-1975). Tesis Doctoral (Universidad de Valladolid, 1996); Rafael Valls Montés, «Las imágenes en los manuales escolares españoles de historia, ¿ilustraciones o documentos?», Iber. Revista de Didáctica de las Ciencias Sociales, Geografía e Historia, 4 (1995): 105-109.

69 Prendes, «La imágenes en los libros de texto», 101. 
aparece en el libro de Wenceslao Ezquerra de 1972 quien en el prólogo afirma: «Al ofrecer a los señores maestros y educadores esta edición de "NUEVAS LETRAS", muy corregida y mejorada en sus condiciones pedagógicas y presentación».$^{70}$ Otro ejemplo clarificador se encuentra en Ventanal, de la Editorial Escuela Española, que venía editando textos desde las primeras décadas del franquismo y que, en un giro en su concepción educativa, publicó el siguiente prólogo:

\section{ANOTACIONES DE LOS AUTORES}

- VENTANAL quiere sintetizar las ventajas del globalismo -tan defendido por la moderna psicologia - y el método si. labico, muy acorde con la estructura del idioma español.

- Tiene el apoyo de ilustraciones, como es obligado en un medio didáctico que ha de servir al párvulo, hoy más que nunca inmerso en el sugestivo mundo de la imagen. Pero no utiliza ésta como un artificio para asociaciones sin sentido que lo convirtieran en una especie de struco para ensen̂ar a leers.

- La utilización inicial, y consiguiente, de frases de sencilla construcción proporciona al método un carácter más natural, y al niño el efecto estimulante de *saber leers desde que empieza su aprendizaje.

- Las frases -y las palabras que las componen- hacen referencia continua a experiencias de la vida infantil. Los protagonistas - personas, animales y cosas - que van apareciendo en las Cartillas de =VENTANAL > pertenecen $\longrightarrow$ pueden incorporarse en seguida- al campo de los conocimientos inmediatos del nin̂o.

$$
\text { (pasa al final) }
$$

Figura 5. Manuel Sanjuán y José Vázquez, Ventanal

(Madrid: Escuela Española, 1974).

\footnotetext{
${ }^{70}$ Wenceslao Ezquerra, Nuevas letras (s.l., s.e., 1972).
} 
En los diversos textos preliminares de sus obras escolares, los autores indican aspectos relativos al método, al medio didáctico y a los contenidos elegidos, en este caso útiles y cercanos al mundo del niño, sin aludir a ningún contenido emocional ni socio-político. Este hecho es casi generalizado en los textos de lectura de la segunda etapa del tardofranquismo. El grado de adoctrinamiento con respecto a la época anterior va desapareciendo, tanto en contenidos político-religiosos como en su dimensión emocional. Por otro lado, el lenguaje textual que se emplea en la redacción es más inocuo y neutro, y en la mayor parte de los casos está dirigido a cumplir el objetivo primordial del libro: enseñar a leer. La gran mayoría de las ilustraciones son también asépticas en cuanto a los contenidos emocionales o adoctrinadores, y se limitan a ejemplificar o a ilustrar la lección que se intenta transmitir; en este caso también a los fonemas que se pretenden enseñar. Sin embargo, en ocasiones se pueden leer en los prólogos alusiones directas a la importancia que tiene aprender a leer con alegría, casi las únicas referencias directas al mundo emocional encaminadas a crear conductas y motivaciones positivas ante el estudio y la lectura, pero no dirigidas a la formación sociopolítica del futuro ciudadano. El libro de Wenceslao Ezquerra de 1972, Nuevas letras, nos sirve de nuevo de ejemplo; en él se sugiere «que el niño adquiera el mecanismo de la lectura y la escritura alegremente, como un juego más de los que él se trae entre manos». ${ }^{71}$

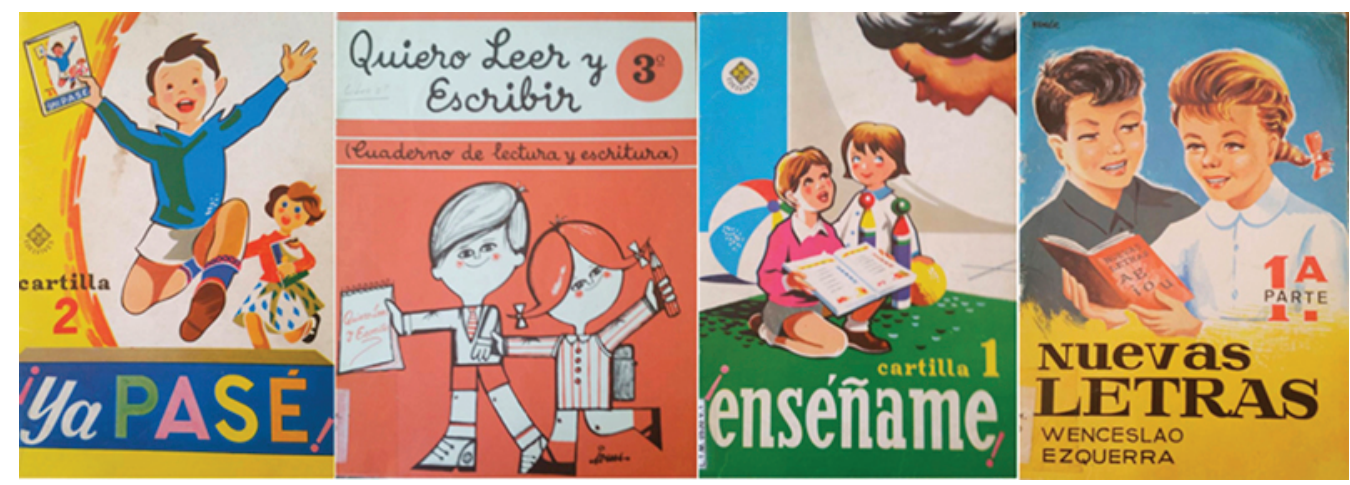

Figura 6. Portadas Libros de Lectura.

71 Ezquerra, Nuevas letras. 
Este sentimiento de complacencia y de satisfacción hacia la lectura es evidente en las ilustraciones de todos los manuales que representan al niño experimentando esta emoción, especialmente en las portadas de los manuales. En la mayoría de las portadas se muestran niños con gesto sonriente y alegre ante el hecho de aprender. En los casos en los que aparecen más de un personaje la relación entre ellos trasmite armonía, concordia y compañerismo. Lejos quedan las portadas de libros de lectura con símbolos de España, héroes, santos y mártires.

La presencia en los manuales escolares de emociones como la violencia, la agresividad, la crueldad o la compasión, tan frecuentes en las primeras décadas del régimen, especialmente en los libros de lecturas históricas, pero también en los libros de lecturas generales, contrasta con su desaparición casi total. Tan solo hemos encontrado un libro de la editorial Anaya, de 1976, con una imagen en la que aparecen niños peleándose entre sí. No aparecen en ningún caso alusiones en las imágenes a guerras, martirios de santos o castigos a pecadores. La única alusión a este tipo de contenidos que aparece de forma repetida es utilizando el deporte, especialmente el boxeo como excusa y al aprender la letra «x».

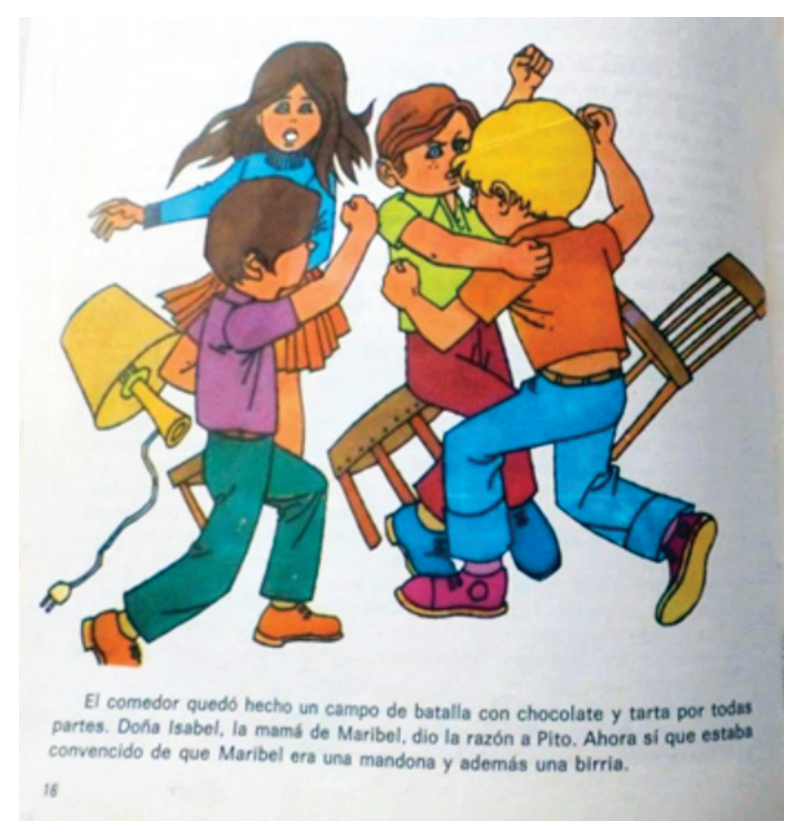

Figura 7. Mundo Nuevo (Madrid: Anaya, 1976), 16. 


\section{La literatura infantil y los libros de lectura}

En los libros de lectura más avanzados, compuestos por textos más complejos y en consonancia con la apertura del régimen al exterior, se fueron introduciendo fragmentos de literatura extranjera: Robinson Crusoe, Los viajes de Gulliver, El libro de la selva y La vuelta al mundo en 80 días. La novedad indica uno de los cambios fundamentales en la concepción del libro de lectura y el giro hacia otro mundo emocional. Durante el franquismo el libro de lectura se vinculó a determinadas disciplinas, especialmente a aquellas con contenidos propios del nacional-catolicismo: historia, geografía, literatura (adulta), formación política, social, familiar y religiosa. Constituyó un tipo consolidado de libro de texto en formato de lecturas. En el segundo tardofranquismo afloraron libros de lectura que incorporaban piezas de la literatura infantil y que abrían paso a la ficción, a la fantasía y a la imaginación. Los libros de lectura comenzaron a constituirse en libros de fomento de la lectura. Un estudio comprobó que la ficción literaria desarrolla y mejora las habilidades de comprensión de las emociones de otras personas, lo que se conoce como empatía. Aunque la investigación reconocía la necesidad de perfeccionar las diferencias entre los distintos tipos de ficción, literaria y popular, ${ }^{72}$ era posible concluir que la incorporación de extractos literarios de ficción podría contribuir al desarrollo escolar de ese tipo de emociones sociales.

\section{CONCLUSIONES}

La investigación muestra la evolución del libro de lectura a lo largo del tardofranquismo, partiendo de las décadas anteriores con el fin de detectar continuidades y rupturas. Se comprueba que el libro de lectura pasó de ser un instrumento político-educativo, empleado en la transmisión del componente emocional de los conocimientos socio-políticos y religiosos, a un recurso didáctico para la enseñanza y la práctica de la lectura y la iniciación a la educación literaria. Sin embargo, la transición fue lenta y durante el tardofranquismo todavía convivieron las distintas concepciones del libro de lectura como vehículo de adoctrinamiento emocional socio-político y como libro de lectura infantil. El uso instrumental del libro de lectura por el régi-

${ }^{72}$ David Comer Kidd y Emanuele Castano, «Reading Literary Fiction Improves Theory of Mind», Sciencexpress, 3 (2003): 1-6. 
men franquista fue similar al del Deutsches Lesebuch (libro de lectura alemán) durante el nazismo. "Every aspect of nazi ideology and propaganda seems to be presented here; 365 pages draw on the great treasury of German literature and culture —for Volk und Führer». ${ }^{73}$

A partir de la LGE de 1970 comenzaron a surgir nuevos libros de lectura aunque con restos evidentes del período anterior, moldeador de la estructura emocional y de la dimensión afectiva de la socialización política. A raíz del surgimiento de los equipos de autores de los grandes grupos editoriales ese modelo fue desapareciendo. Según fue muriendo el libro de lectura personal de autor con fuerte intención adoctrinadora, nació un libro de lectura diferente al editado hasta ese momento, que prestaba atención a la literatura pueril, al mundo infantil, a la imaginación, a la fantasía, y se alejaba del mundo político adulto. Sin embargo, este hecho no quiere decir que tuviera lugar un vaciado de contenido emocional completo y radical, sino que las emociones y los sentimientos que se transmitían, proyectaban y enseñaban eran otros. Fueron convirtiéndose en objetos materiales de la cultura escolar más propios del joven sujeto lector. El estudio muestra por tanto cómo el libro de lectura, a medida que avanzaron las décadas del franquismo, fue dejando de ser un instrumento al servicio del régimen y transformándose en un recurso didáctico con fines prioritariamente pedagógicos.

Patterson, Cormack y Green aclaran que durante la primera parte del siglo xix la idea de que la lectura era simplemente una práctica pasiva que incluía una recepción acrítica del texto empezó a ser cuestionada por los educadores que buscaban las formas de proporcionar un acceso masivo a la lectura. ${ }^{74}$ Algo similar tuvo lugar en el tardofranquismo por parte de la comunidad educativa. Los nuevos libros de lectura permitían una aproximación diferente del sujeto lector al texto, abriendo la puerta a la actividad interna, a la interpretación y apreciación del texto y al goce de la lectura.

En 1975, Juan Navarro Higuera, prolífico autor de manuales escolares, afirmaba que la lectura incrementa sus opciones en relación con el oficio

\footnotetext{
73 «Cada aspecto de la ideología y propaganda nazi parece estar presente aquí; 365 páginas recurren al tesoro de la literatura y cultura alemanas - para el pueblo y el Führer». Arthur Hearnden (ed.), The British in Germany. Educational Reconstruction after 1945 (London: Hamish Hamilton, 1978), 128.

${ }^{74}$ Annette Joyce Patterson, Phillip Anton Cormack y William Charles Green, «The child, the text and the teacher. Reading primers and reading instruction», Paedagogica Historica: International Journal of the History of Education, 4 (2), (2012): 192.
} 
mecanicista que le otorgaba la escuela tradicional. Según él, la lectura asume un carácter polivalente que le brinda mayores posibilidades aplicativas y de formación. ${ }^{75}$ Esta evolución técnica de la enseñanza y aprendizaje de la lectura favorece que se vincule a la disciplina del lenguaje y la literatura alejándose de otras disciplinas de carácter más adoctrinador como la historia o la religión. De esta forma los contenidos emocionales asociados a la socialización política desaparecen pausadamente de este tipo de textos.

El examen que se hace de los libros de lectura del franquismo es necesario y para muchos adultos de hoy es una tarea difícil que requiere un trabajo de «straniamento» (extrañamiento o alejamiento), como bien apunta Umberto Eco, porque «la fiducia che proviamo, di istinto, per il libro di lettura, non è dovuta ai meriti di quest'ultimo, ma alle nostre debolezze, che i libri di lettura hanno creato e alimentato». ${ }^{76}$

\section{Nota sobre las autoras:}

Ana M. ${ }^{a}$ Badanelli Rubio es Doctora en Ciencias de la Educación por la Universidad Nacional de Educación a Distancia, Madrid, Febrero 2004. Es Profesora Contratada Doctora y Secretaria del Departamento de Historia de la Educación y Educación Comparada de la Facultad de Educación de la UNED. Es Coordinadora General del «Centro de Investigación MANES» desde octubre del 2001. Su experiencia investigadora se ha centrado en el campo de la historia del currículo y de la cultura escolar, campos que se han consolidado como parte de la renovación de la Historia de la Educación en las últimas décadas. Sus estudios se centran fundamentalmente en dos fuentes: manuales

\footnotetext{
75 Juan Navarro Hoguera, «Libros de lectura, clases y usos de los mismos», Vida Escolar, 165-166 (1975): 10.

${ }^{76}$ Marisa Bonazzi y Umberto Eco, I pampini bugiardi. Indagine sui libri al di sopra di ogni sospetto: $i$ testi delle scuole elementari (Firenze: Guaraldi Editore, 1972), 7. La traducción se leería así: «La confianza que sentimos, por instinto, hacia el libro de lectura no se debe a sus méritos, sino a nuestra debilidades, que los propios libros de lectura han creado y alimentado».
} 
escolares y cuadernos escolares, fuentes que favorecen la comprensión de la historia de la escuela. Entre sus publicaciones destacan: Badanelli Rubio, Ana M. ${ }^{\text {a: }}$ "Representing two worlds: illustrations in Spanish textbooks for the teaching of religion and object lessons (1900-1970)», History of Education, 41, 3 (2012): 303-338 o Meda, Juri y Badanelli Rubio, Ana M. ${ }^{a}$ (eds.): La historia escolar en Italia y en España: balance y perspectivas (Macerata: Edizioni Università di Macerata, 2013).

Kira Mahamud Angulo es profesora en el Departamento de Historia de la Educación y Educación Comparada, en la Facultad de Educación de la UNED y miembro del equipo investigador del Centro de Investigación MANES. Ha participado en varios proyectos de investigación nacionales y europeos y realizado estancias de investigación postdoctoral en el Institute of Education de la Universidad de Londres (Inglaterra) y en el Georg Eckert Institute for International Textbook Research, en Braunschweig (Alemania). Entre sus últimas publicaciones se encuentra: Kira Mahamud \& María José Martínez Ruiz-Funes, "Reconstructing the life histories of Spanish primary school teachers: a novel approach for the study of the teaching profession and school culture», History of Education, 43, 6 (2014): 793819. Sus líneas de investigación actuales son la historia y política de la educación, la cultura escolar material e inmaterial, las historias de vida de maestros y las metodologías de análisis de fuentes primarias escritas y orales. 